\title{
A Large-Scale Study of Daily Information Needs Captured In Situ
}

\author{
KAREN CHURCH, MAURO CHERUBINI, and NURIA OLIVER, Telefónica Research
}

\begin{abstract}
The goal of this work is to provide a fundamental understanding of the daily information needs of people through a large-scale, in-depth, quantitative investigation. To this end, we have conducted one of the most comprehensive studies of information needs to date, spanning a 3-month period and involving more than 100 users. The study employed a contextual experience sampling method, a snippet-based diary technique using SMS technology, and an online Web diary to gather in situ insights into the types of needs that occur from day to day, how those needs are addressed, and how contextual, technological, and demographic factors impact on those needs. Our results not only complement earlier studies but also provide a new understanding of the intricacies of people's daily information needs.
\end{abstract}

Categories and Subject Descriptors: H.m [Information Systems]: Miscellaneous

General Terms: Design, Experimentation, Human Factors

Additional Key Words and Phrases: Information needs, mobile needs, experience sampling method, ESM, context, diary study, SMS, user behavior, mobile computing

\section{ACM Reference Format:}

Karen Church, Mauro Cherubini, and Nuria Oliver. 2014. A large-scale study of daily information needs captured in situ. ACM Trans. Comput.-Hum. Interact. 21, 2, Article 10 (February 2014), 46 pages.

DOI: http://dx.doi.org/10.1145/2552193

\section{INTRODUCTION}

People often encounter a diverse range of context-sensitive information needs in their day-to-day lives. Deciding which movie to see in the cinema with friends, finding the location of a nearby restaurant, learning the latest football results, and getting information on the time of the next bus home are all examples of the needs we encounter every day. At times the information desired is essential to the task at hand, and in many cases, people require assistance to address the need in question. Technology has become one such source of assisting people in coping with their daily information needs.

Over the past 10 years, we have witnessed huge advances in mobile technology in particular. Improvements in mobile networks, the growing popularity of mobile applications, and significant advances in mobile handset technology have contributed to a dramatic increase in the use of these portable communications devices to access a wealth of information while on the move. ${ }^{1}$ This shift in how users access and consume

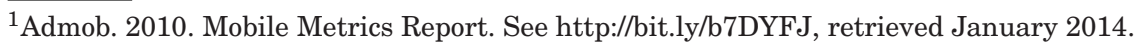

This work was conducted while both Karen Church and Mauro Cherubini were employed at Telefonica Research. Karen Church is currently working at Yahoo Labs. Mauro Cherubini is currently working at Google Inc.

Authors' addresses: Karen Church, 701 First Avenue, Sunnyvale, CA 94089. kchurch@yahoo-inc.com; Mauro Cherubini, Google Inc.

Permission to make digital or hard copies of part or all of this work for personal or classroom use is granted without fee provided that copies are not made or distributed for profit or commercial advantage and that copies show this notice on the first page or initial screen of a display along with the full citation. Copyrights for components of this work owned by others than ACM must be honored. Abstracting with credit is permitted. To copy otherwise, to republish, to post on servers, to redistribute to lists, or to use any component of this work in other works requires prior specific permission and/or a fee. Permissions may be requested from Publications Dept., ACM, Inc., 2 Penn Plaza, Suite 701, New York, NY 10121-0701 USA, fax +1 (212) 869-0481, or permissions@acm.org.

(c) 2014 ACM 1073-0516/2014/02-ART10 $\$ 15.00$

DOI: http://dx.doi.org/10.1145/2552193 
content through their mobile devices is having a profound impact on how users address their daily information needs.

Several recent studies have highlighted interesting insights into the types of information needs that occur in mobile settings. These studies have helped us understand human information needs across a variety of contexts and have pointed to a number of important implications for future mobile services. However, the majority of these studies are relatively small in terms of scope, scale, and duration, and many open research questions remain.

The goal of this work is to provide a fundamental understanding of daily information needs through a large-scale, in-depth, quantitative investigation conducted in situ. Large-scale observational studies can shed light on unanswered questions regarding why information needs arise, the challenges people face in addressing their information needs, and how external factors influence people's daily needs. These insights could point to new opportunities for future information-based services. To this end, we conducted one of the most comprehensive studies of information needs to date, spanning a 3-month period in Spain, involving more than 100 users, and covering daily information needs generated in both mobile and nonmobile settings. Our study employed a contextual Experience Sampling Method (ESM), a snippet-based diary technique using SMS, and an online diary to gain insights into the types of needs that arise on a day-to-day basis and how those needs are addressed. The study resulted in almost 12,000 SMS snippets and more than 9,000 associated diary entries.

In addition to the study and methodology adopted, the main contributions of this article are as follows:

(1) We shed new light on the characteristics of daily information needs with a comprehensive taxonomy of information needs and compare our findings to past related work. This taxonomy is based on a taxonomy adapted from Dearman et al. [2008]. Our classification of information needs shows that although many of Dearman et al.'s original categories hold, new categories of information needs have emerged.

(2) We present an in-depth investigation into how information needs are addressed and why some needs are left unsatisfied by devising a comprehensive taxonomy of the techniques that our participants adopted in satisfying their information needs. Whereas past work has focused on two modalities of satisfying needs, namely, Internet access or asking people for help, our results show that people employ a wide range of modalities to satisfy their information needs and that the modality chosen to satisfy their need depends on the type of information need.

(3) We analyze the impact of technology, context, and demographics on the types of needs that arise and how those needs are addressed, namely, mobile phone type, location, and gender. We show how information needs and the means chosen to satisfy those needs differ between (a) men and women, (b) smartphone and feature phone users, and (c) mobile and fixed locations (e.g., home, work). To the best of our knowledge, this study is the first to look at the impact of such contextual dimensions on user behaviors, specifically the role of gender and mobile phone type.

The rest of this article is organized as follows. We begin with a review of related work and highlight our main research questions in Section 2. Section 3 presents our study methodology. Key results from our analyses are described in Section 4. Finally, we highlight the main research and design implications of our work in Section 5.

\section{RELATED WORK AND RESEARCH QUESTIONS}

The goal of this work is to enrich our understanding of the daily information needs of people. In this section, we provide a comprehensive review of past related work in this space and outline our core research questions. 


\subsection{Definition of Information Needs}

One of the most salient aspects of the current panorama of studies on information needs is the lack of a common definition of what information needs are. Research on information-seeking behavior in libraries conducted in the 1960s by Robert Taylor described four varying levels of information needs based on how well those need can be articulated: visceral, conscious, formalized, and compromised [Taylor 1968]. Other definitions focused on the Information Retrieval (IR) paradigm, where information needs are seen as "combinations of ideas such as what the target information might look like, where it might be found, or how one might go about tracking it down" [Campbell 2000]. Some authors have implicitly associated information needs with information that is typically searched and obtained via the mobile Internet [Church and Smyth 2009; Hinze et al. 2010] or with whether the person expressing the need could recall the information [Heimonen 2009]: "need for a piece of information that you cannot recall from memory or that is not immediately available to you." Recently, other researchers have restricted their studies to information needs that could be fulfilled by mobile phones only [Chua et al. 2011] or enlarged the scope of their investigation to needs whose goals go beyond increasing one's personal knowledge about things [Cherubini et al. 2011]. Thus, this past work highlights the lack of a single, consistent notion of an information need.

In this study, rather than rigidly defining the scope of an information need, we decided to take a somewhat explorative stance and adopted the definition originally proposed by Dearman et al. [2008]: "an information need is any information that is required for a task, or to satisfy the curiosity of the mind, regardless of whether the need is satisfied or not." Hence, we focus on needs that may or may not have an informative nature and on needs that are generated through mobile technology as well as those that are expressed by other means.

\subsection{Types of Information Needs}

There have been a number of recent studies focusing on user-centric approaches to understanding the nature of information needs and particularly the types of information needs people have in their daily life.

Sohn et al. [2008] conducted a 2-week diary study of how and why information needs arise when users are on the go. They received diary entries via SMS and allowed their 20 participants to complete their entries through a Web interface. They collected 421 diary entries and identified 16 broad information need categories. Dearman et al. [2008] carried out a 4-week paper-based diary study on how information needs can be supported by individuals in their social network. They also involved 20 participants, who produced around 1,290 entries. This corpus was organized in 22 microcategories and 9 macrocategories of daily information needs.

In 2009, three independent groups of researchers published results shedding light on information needs. Church and Smyth [2009] conducted a paper-based diary study to understand the intent behind the information needs of mobile users in particular. The study involved 20 participants over a 4-week period. Through this study, they collected 405 diary entries that were organized into 17 categories. Amin et al. [2009] conducted a study on location-based mobile search involving 9 participants for 12 days. To understand how people express location-based information needs, they asked participants to use a Web-based diary and instrumented mobile devices to collect search event logs. They collected a dataset of 347 queries that were organized into 14 categories. Although these studies recruited average users, Heimonen [2009] conducted a study with active mobile Internet users and found an increased number of situations in which information needs were addressed using mobile devices. He used a Web diary 
technique and involved 9 participants over the course of 4 weeks. The collected dataset contained 147 entries that were organized into 15 categories.

Hinze et al. [2010] addressed the kind of questions that people would like to answer through mobile devices and found that contextual factors such location, conversation, and activity strongly influence mobile information needs. They used a paper diary technique and involved 12 participants over the course of 1 week. Through this technique, they collected 220 entries that were organized into 21 categories. Chen and Qi [2010] reported the results of a study focusing on the information needs that people express during leisure traveling. They used a paper diary technique and involved 14 participants during their vacation time (maximum duration of the study was 17 days). They collected 204 entries that were organized into 10 categories. Cherubini et al. [2011] conducted a 3-week video and paper diary study on information needs of 8 smartphone users of contextual applications (e.g., a navigation application). They collected 114 diary entries, several hours of video diary entries, and recordings of interviews. This material was organized into 24 categories.

Finally, Komaki et al. [2012] conducted a 4-week diary study on the impact of mobile context on the information needs and search behaviors of 26 users in Japan, focusing particularly on the situations when users failed to find the information needed using mobile search. The authors identified 8 categories of mobile information needs that map to use of mobile search engines. When we look at the topical list of information needs generated by prior work, we realize that many categories overlap, but there are others that are unique and appear in only some of the studies, such as the "state of an asset" category identified by Dearman et al. [2008]—for example, "Did I forget to turn the TV off?"

We compared the different coding schemes used in previous work by using the definitions and examples available in the respective papers. This comparison is shown in Table I. The matching of these information need categories was performed independently by the first two authors of this article. We had few nominal disagreements $(<3 \%)$ that were discussed and solved. Note that some categories could not be mapped fully due to differences in both naming and definition.

The lack of a consistent taxonomy in previous work made us question whether this could have been caused by the variety of length, sample size, and collected datasets of previous studies. We decided to reproduce the results of these experiments by applying a more quantitative framework and a longitudinal approach. Our goal is provide a more comprehensive characterization of daily information needs.

Hence, we pose our first research question as follows: RQ1-What are the types of information needs expressed by people in their daily life?

\subsection{How and When Are Needs Satisfied?}

Sohn et al. [2008] found that $30 \%$ of mobile information needs were not answered at all, whereas $25 \%$ were postponed and the remaining $45 \%$ were addressed at the time they arose. Participants in Sohn's study reported eight different ways that they satisfied their needs, including asking someone, a proxy, or a source (47\% of the time); using an Internet resource, Web, or map (40\%); going to the actual location where the answer could be found (5\%); and other (9\%).

Different numbers were obtained by Dearman et al. [2008], who found that $27 \%$ of the entries were answered immediately, whereas $41 \%$ were addressed later and $32 \%$ were not addressed at all. They also found that $51 \%$ of the needs were answered by asking someone, checking the Internet (37\%), physically going there (5\%), and other means (6\%). Heimonen [2009] found yet a different breakdown: virtually all of the information needs in their dataset were addressed at the time they emerged. Participants in Heimonen's study addressed their information needs using six methods. Only 


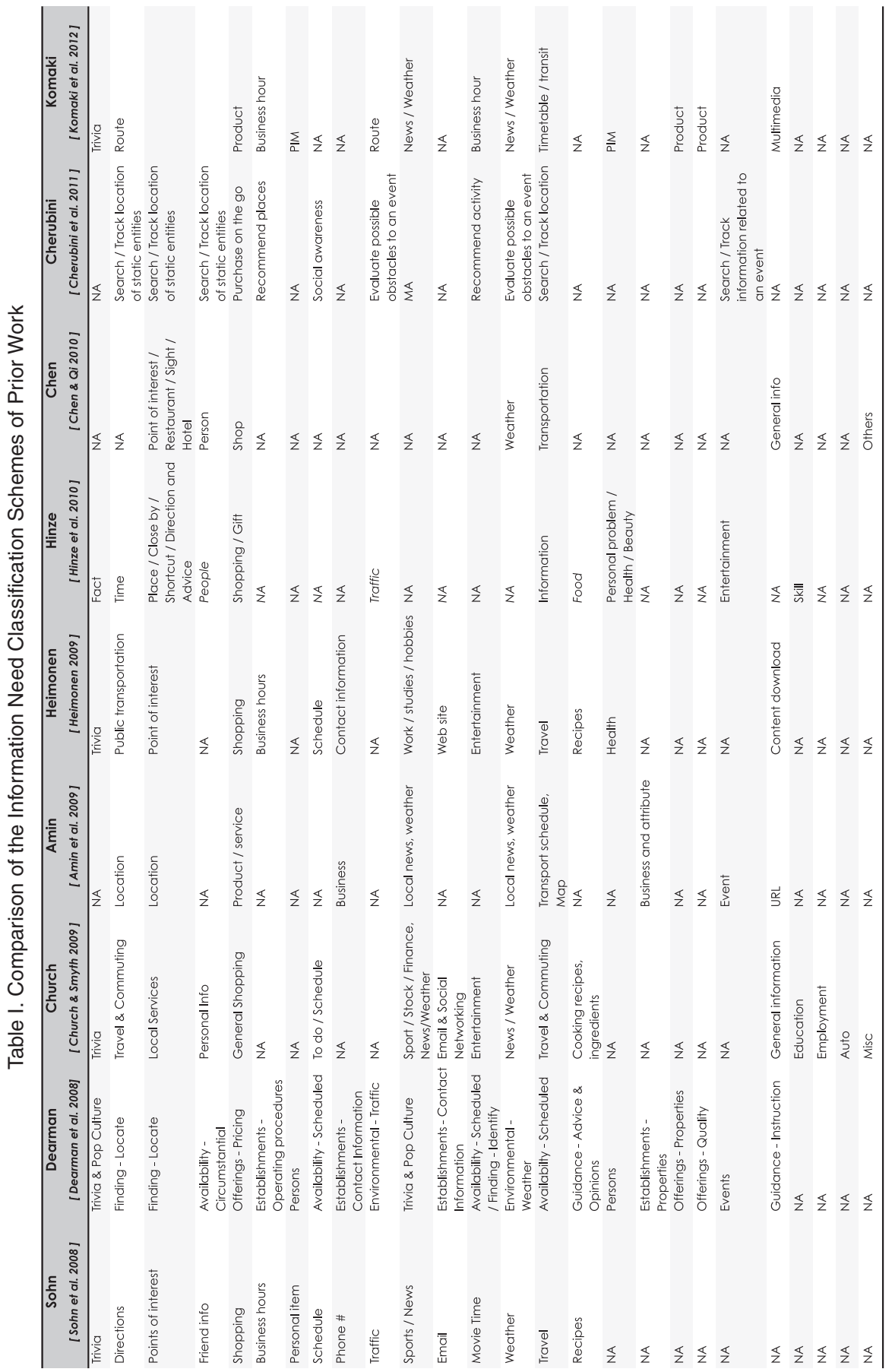


$3 \%$ asked someone. More often, they found the desired information using a native app, Web services, or search engines (94\%). It was only in $2 \%$ of the cases that they used an SMS service. Komaki et al. [2012] focused explicitly on understanding information needs addressed using the mobile Web and found that $20 \%$ of information needs failed when users attempted to address those needs via mobile search. Finally, Chua et al. [2011] conducted a 1-week diary study of 20 users focusing on the use of mobile phones for satisfying mobile information needs and found that people's perceptions regarding the use of mobile phones influenced their ability to fulfill those needs. Factors like the users' proficiency with mobile technology, perceived ease of use, cost of services, urgency of the information need, responsiveness of the mobile phone, and the privacy of data all play a role.

These findings are certainly relevant to our understanding of the current coping mechanisms of people, but they still offer a somewhat fuzzy picture of the different strategies that people adopt to satisfy their specific information needs. Given the scale and scope of our study, we would like to investigate how users address their information needs in more depth. Our goal is to devise a structured framework for understanding how people currently address their daily information needs and to shed light on the information needs that people encounter on a daily basis that they have difficulties in addressing. We therefore pose our second research question: RQ2-What proportion of daily information needs are satisfied, and what strategies are adopted by users to address these needs?

\subsection{The Impact of Context on Daily Information Needs}

In terms of context, most of previous work has recognized the importance of four contextual variables related to mobile information needs: (1) the activity of the person at the time the needs arose, (2) the location of the person at the time the need arose, (3) the time of day when the need arose, and (4) the conversation or social activity the person was involved in at that particular time. Sohn et al. [2008] found that $72 \%$ of the reported information needs were prompted by at least one contextual factor.

Church and Smyth [2009] found that 30\% of the identified information needs were location dependent and a number of information needs had temporal dependenciesthat is, participants were often looking for fresh content. Additionally, activity played a strong role in many information needs (e.g., requests for traffic updates). Many of the identified needs arose while talking to friends or family, thus revealing the importance of the social context. Similar findings were reported by Tamminen et al. [2004], Chua et al. [2011], and Teevan et al. [2011]. Komaki et al. [2012] found that not only were users' information needs and subsequent mobile searches influenced by contextual factors like location, but the success rates in addressing those needs were also influenced by context. For example, the use of mobile search to address needs was less successful in mobile environments compared to when users were at home.

Overall, these studies differed in the frequencies with which the observed needs were influenced by contextual factors. Furthermore, it is likely that other contextual, demographic, and technological factors are likely to influence daily information needs and are yet to be explored. To address this gap in the existing literature, in this study we explore the impact of gender, mobile phone type, and location on the way that people experience and address their information needs.

To the best of our knowledge, our study is the first to look explicitly at the role that gender and availability of mobile Internet access plays on how needs are satisfied. Hence, we pose our third research question: RQ3-What is the impact of contextual, demographic, and technological parameters like gender, mobile phone type, and location on the types of information needs that arise and, likewise, how those needs are addressed? 
In the following section, we describe our study methodology, followed by an-depth discussion of our results and their implications on future services, focusing particularly on mobile services.

\section{STUDY METHODOLOGY}

One of the key goals of our study was to capture valid, real-world experiences of information needs in situ over a longitudinal time period. We considered a number of approaches in designing our study. After careful consideration, weighing up the pros and cons of multiple approaches, we opted to employ a snippet-based diary study [Brandt et al. 2007] combined with a refined version of the ESM (i.e., rESM) [Cherubini and Oliver 2009]. We describe this methodology in more detail in the following sections.

\subsection{Our Methodology}

Diary studies have a long tradition in Human-Computer Interaction (HCI) [Grinter and Eldridge 2003; Colbert 2007]. They allow participants to handle the capturing of data in almost any situation, thus resulting in potentially large amounts of ecologically valid user data. Another advantage of using diary studies is that they require little effort or cost to be deployed, and they support the generalization of results. One of the drawbacks of this method, however, is that it requires participants to remember to record their diary entries, which can be particularly challenging in active conditions or mobile environments [Palen and Salzman 2002] and can lead to missing or incomplete diary entries. This is why in recent years, researchers have proposed alternative strategies to support the creation of diary entries in mobile situations where participants are often unable to invest sufficient time in generating thorough diary entries (e.g., voice diaries [Palen and Salzman 2002]; recorded calls [Bentley and Metcalf 2008]; and combinations of SMS, MMS, and Audio snippets with online Web diaries [Brandt et al. 2007]).

The snippet-based diary technique, proposed by Brandt et al. [2007], had the specific aim of lowering the burden associated with conducting in situ diary studies. This technique allows participants to capture small snippets of information in the wildthat is, bits of text, audio, or pictures using a mobile phone through SMS or MMS messaging, or by leaving a voicemail message. Participants then access a Web site to review their snippets and complete structured diary entries at their convenience. Hence, the snippets serve as prompts or reminders to participants while answering a series of structured questions in relation to what they were doing at the time they captured the snippet in question. This approach provides some of the ecological validity of traditional diary studies while lowering the overhead associated with capturing and generating those diary entries.

In their evaluation of the snippet-based diary technique, Brandt et al. [2007] found that when recording diary entries in situ, text messaging was the preferred modality. Thus, we chose a similar approach, and our participants captured snippets of text reflecting their information needs via SMS messages sent to a free SMS short-code service $^{2}$ that we set up for the duration of the study. Participants then accessed an online Web diary each evening that listed all SMS snippets they generated throughout the day. Participants were asked to fill in a diary entry and answer a series of structured questions regarding each of the captured snippets. In this way, our participants did not need to carry an extra device or a paper diary.

Although snippet-based diary approaches certainly lower the burden of in situ data capture, they still rely heavily on participants' memory. The ESM is a research method that tackles this issue explicitly by asking participants to report on their experiences at specific points throughout the day. The method was originally developed in the

\footnotetext{
${ }^{2}$ That is, all SMS snippets sent and received throughout the study were free of charge.
} 
psychology domain [Barrett and Barrett 2001] and has been adapted successfully in many studies of HCI [Intille et al. 2003; Consolvo and Walker 2003; Iachello et al. 2006; Fischer 2009]. As highlighted previously [Cherubini and Oliver 2009], the main advantage of ESM is its ability to preserve the ecological validity [Hormuth 1986]. One of the drawbacks of ESM is that subjects are often sampled or probed at random times or with little knowledge of their whereabouts. Therefore, the probing might be invasive or take place at inappropriate times. Hence, refinements to ESM have recently been suggested by modeling the participants' context [Froehlich et al. 2007; Cherubini and Oliver 2009; Vastenburg et al. 2010]. Refined-or contextual-ESMs attempt to go one step further by only probing users at appropriate times or in the right context.

Thus, in this study, we extend the snippet-based diary technique with a contextual ESM to proactively probe users about their information needs in a variety of contexts. In our study, we use knowledge about the participants' daily routines as a form of context. Past research in the reality mining space has shown that people are essentially creatures of habit, following similar routines, day after day [Eagle and Pentland 2006]. Thus, we use this prior knowledge about the general habits and routines of our participants to ask them about their information needs at the most appropriate times and in a wide variety of situations and locations.

In order to capture information about daily routines, we built an interactive Web page (shown in Figure 1) where participants could enter details of their daily routines and locations. Participants could choose from a set of baseline locations or activities, such as at home, at work, or commuting, or they could add their own unique locations or activities. Participants first specify whether they are willing to receive an SMS at these locations or during these activities and indicate whether this place or activity has a specific location by marking that location on a Google map (Figure 1(a)). Next, participants enter the times of day and days of the week when they are usually at these locations or engaged in these activities. Finally, participants could specify times of the day or days of the week when they did not want to be disturbed with an SMS message (Figure 1(b)). Once complete, we had a snapshot of each participant's daily routines.

Using this scheduling information, we designed and built a contextual experience sampling algorithm that determines if and when to send an SMS probe to each participant. This algorithm was invoked once every hour, every day, for the duration of the study. On each invocation, the algorithm iterates through all participants in our study and checks the participant's current activity and SMS preference based on the information provided in his or her daily routine. If the algorithm determines that it is allowed to send an SMS probe to the participant in question at this point in time, the algorithm will continue with additional checks before sending that probe. Specifically, the algorithm will check the timestamp of the last probe sent to the participant in question, the associated activity of the last probe sent, and the probability of being able to probe the participant at a future point in the day. If the participant was probed recently and during a similar activity, the algorithm will try to wait until a future point in time to send the probe. If the algorithm does determine that an SMS probe should be sent to the participant in question, full details of the probe are logged in a database for future reference by the algorithm-for example, user i.d. of the participant, timestamp of the probe, activity of the probe (based on the participant's daily routine). The algorithm was configured to send a maximum of three SMS probes per day to each participant at different times throughout each day so that we could capture a range of data points and, as such, a range of insights into the types of needs that arise.

\subsection{Participants}

Our participants were recruited using a survey published via a major Web portal in Spain. In the survey, participants were asked a range of questions about their 
(A) Users first tell us about their daily routine by indicating the places / activities they are generally involved in, the location of that place / activity, and whether they are willing to receive an SMS at that place / during that activity.

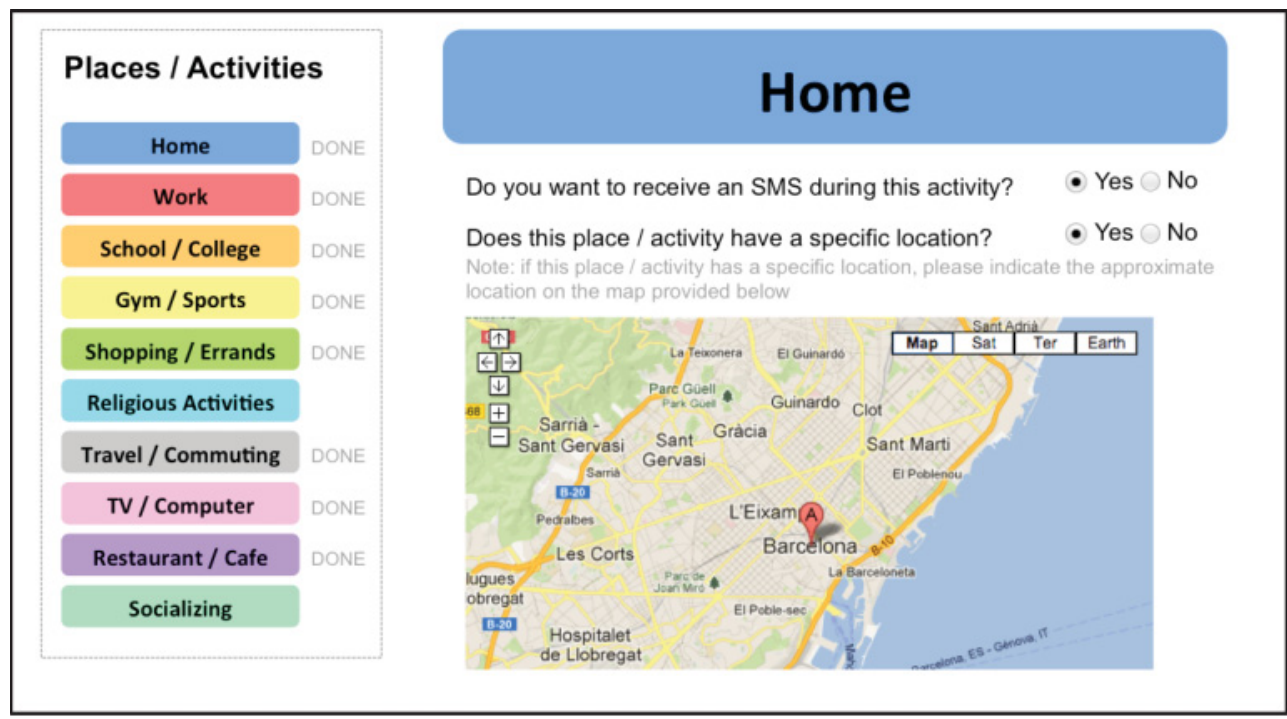

(B) Participants then use calendar-type interface to specify when they are normally at those locations / participating in those activities.

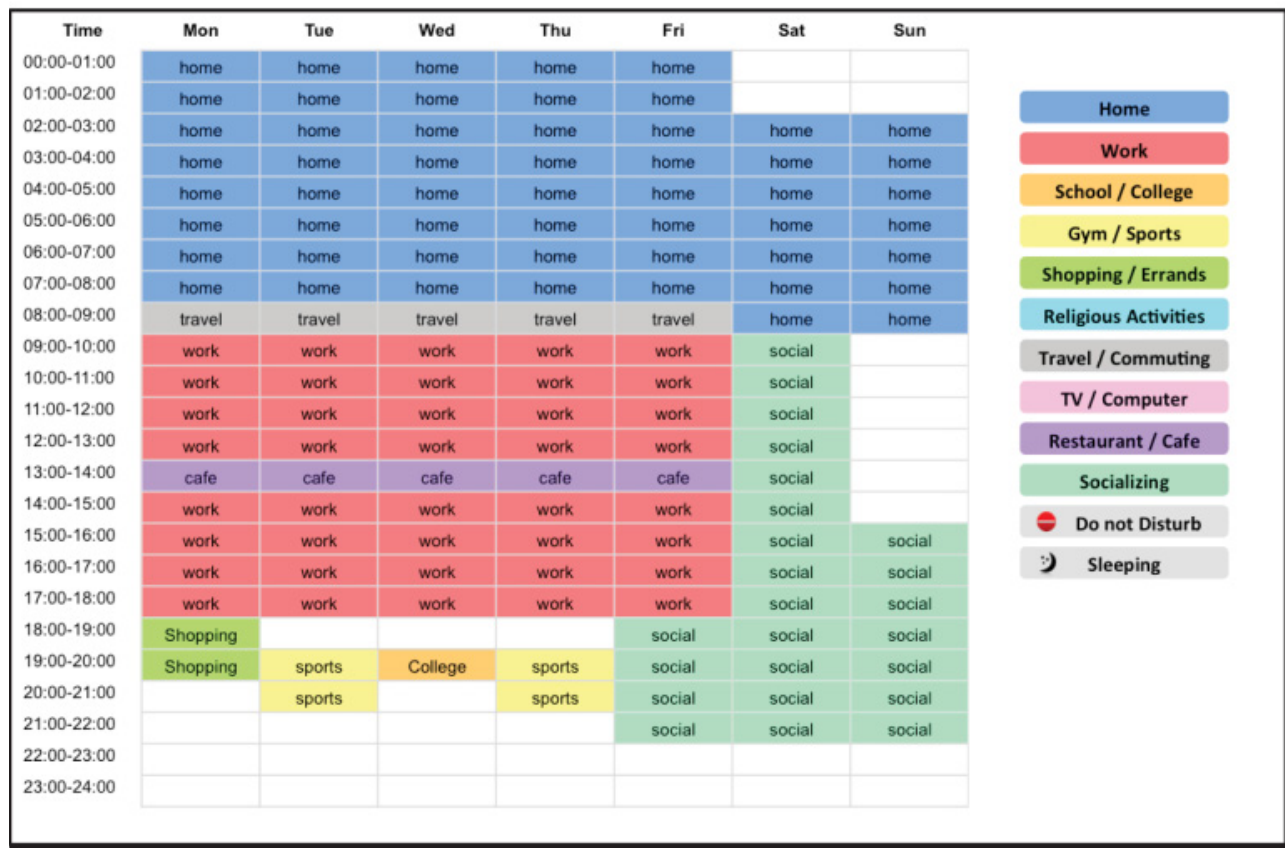

Fig. 1. Web-based interface for capturing information about participants' daily routines. Note that for the user study, this interface was deployed in Spanish. For the purposes of this article, the interface has been translated to English. 
demographics and their mobile usage. We recruited 108 volunteers (66 male and 42 female) who actively use both SMS and the Internet either via a PC or their mobile device. Our participant group included 52 feature phone users and 56 smartphone users. Participants ranged in age between 18 and 58 years, with an average age of 35 years (min: 18, max: 58, Standard Deviation [SD]: 9.2). They came from a diverse range of backgrounds (e.g., IT, engineering, administration, law, production, sales, and education) and had a diverse range of incomes. All of our participants lived in Spain (covering both urban and rural areas) and were native speakers, and the vast majority were of Spanish nationality (all except 6 participants).

\subsection{Procedure}

Before the study began, participants were sent a link to a video describing the study in detail. Participants were informed that we were interested in learning about the types of information needs that they encounter in their daily lives and how they generally address those needs. Rather than rigidly defining the scope of an information need, we told participants to think of an information need as any information that is required for a task, or to satisfy the curiosity of the mind, regardless of whether the need is satisfied or not. The video provided the participants with information on how to fill in their daily routine information, how to respond to SMS probes, and how to access and complete their online diary entries. Participants began by providing details about their daily routines and SMS messaging preferences via the interactive Web page described previously (see Figure 1). Note that this phase of the study was conducted once, and the scheduling information provided in this phase was stored in a database and used for the duration of the study.

After we gathered the required details for all participants regarding their daily routines, the actual study ran for a period of 3 months, from January to April 2011. Participants were informed that they would receive, at most, three SMS probes per day asking them about their information needs. We asked them to respond to these probes with an SMS snippet including relevant details of their information need. This SMS interaction was enabled via a free SMS short-code number set up for the duration of this study. Participants were also told that they were free to send SMS snippets detailing their information needs at any time of day-that is, outside the scope of the SMS probes.

The SMS snippets generated by the participants were sent to a server for processing and were immediately posted to a Web site that acted as the participants' online Web diary. At the end of the day, participants logged into this Web site to answer a series of questions about their snippets. The diary tool was accessible from both mobile and desktop Web browsers and allowed participants to review all SMS snippets that they had sent so far as part of the study. The diary was designed to capture the motivations and intent surrounding information needs while minimizing the time burden on the participants. To achieve this balance, the diary included a mix of open-ended questions, as well as closed questions, where users had to make selections from a given set of possible answers. Following is a list of what we asked participants to record, along with a flag indicating whether the question was open or closed:

(1) The actual information need they were trying to address [open].

(2) Where they were located at the time the need arose [closed].

(3) Who they were with at the time the need arose [closed].

(4) What they were doing at the time the need arose [open].

(5) If their need was satisfied [closed].

(6) How the need was satisfied [open]. 


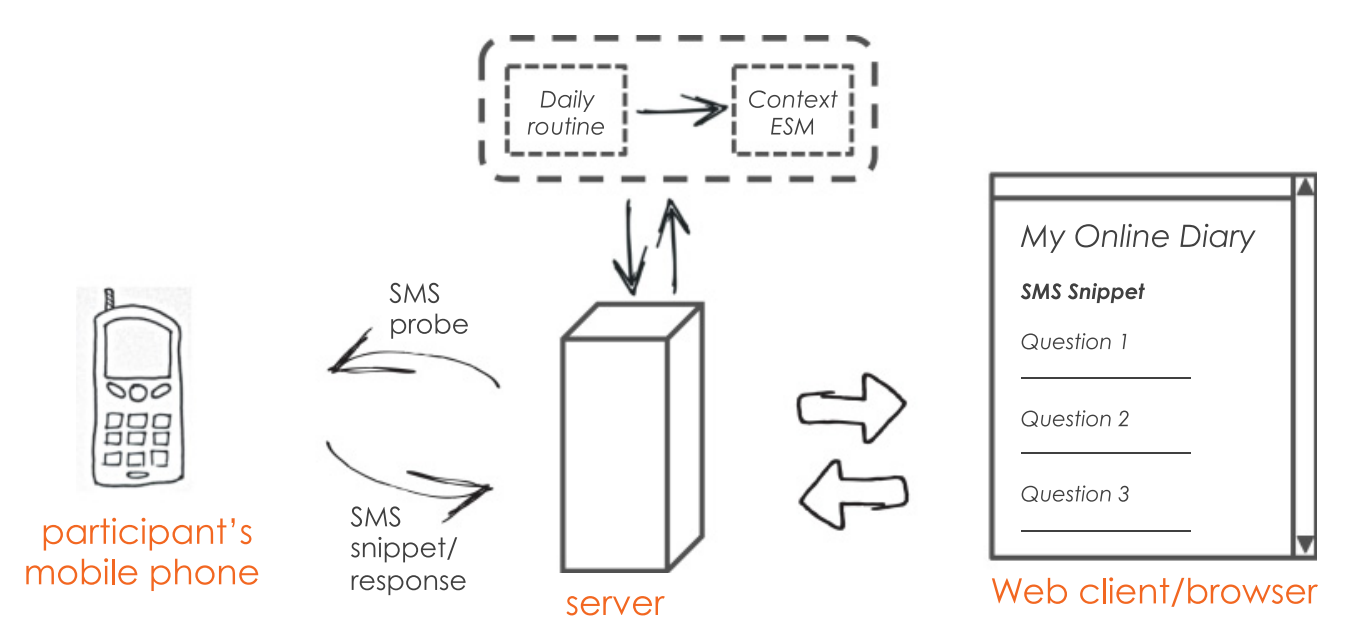

Fig. 2. System diagram showing our implementation of a snippet-based diary technique combined with a contextual ESM.

(7) When the need was satisfied [closed].

(8) If their need was left unsatisfied, why this was the case [open].

Figure 2 shows a system diagram illustrating our entire study methodology and procedure. Along with the SMS probes, we also sent a few emails throughout the study to keep participants informed of the study. At the end of the study, each participant filled in a poststudy questionnaire, where we asked more detailed questions about their mobile information needs and how they satisfy those needs. In terms of incentives, each participant was given a 30 euro gift voucher. We also raffled three prizes among the participants as payment for participating, worth 300,200, and 100 euro, respectively.

In the following sections, we describe the results of our study in detail.

\section{RESULTS}

We begin by describing the dataset that we captured over the 3-month study period along with relevant details on the response rates of our participants to better understand the success of our adopted research methodology.

A total of 26,653 SMS probes were sent to the 108 participants during the course of the study, with an average of 247 SMS probes sent to each user. Our study resulted in 11,507 received SMS snippets, with an average of 106.5 SMS snippets per participant (min: 1, max: 365, SD: 89.3). Thus, 43\% of SMS probes resulted in a response from the participants. As mentioned previously, participants sent their snippets to an SMS short-code number set up explicitly for this study. Using this approach, participants were free to (1) respond to an SMS probe and/or (2) send an SMS snippet to us at any stage throughout the study. All SMS snippets were sent to the same short code; therefore, we could not distinguish between SMS snippets sent in response to an SMS probe versus SMS snippets sent at the users' free will. However, we can assume that SMS snippets received within a certain time period of sending an SMS probe are likely to be a direct response to that SMS probe. Table II shows the number and percentage of SMS snippets received within varying time periods of sending an SMS probe. These results highlight that almost 30\% of the SMS snippets captured during the 3-month study duration were received within 5 minutes of sending an SMS probe. This increases to more than $50 \%$ when we extend the response time to within 45 minutes. Therefore, although we cannot assume that all snippets captured were the result of an SMS probe, a high proportion of SMS snippets were received within 45 minutes of sending a probe. 
Table II. Response Time Between Sending an SMS Probe and Receiving an SMS Response from Participants

\begin{tabular}{lcc}
\hline Within Time Period of SMS Probe & \# SMS Snippets & \% SMS Snippets \\
\hline 5 minutes & 3318 & 28.8 \\
15 minutes & 4399 & 38.2 \\
30 minutes & 5328 & 46.3 \\
45 minutes & 6000 & 52.1 \\
1 hour & 6584 & 57.2 \\
\hline
\end{tabular}

Table III. Percentage of SMS Probes Sent by Activity/Locations as Specified by Participants in Their Daily Routines

\begin{tabular}{lcc}
\hline $\begin{array}{l}\text { Location / Activity from Daily } \\
\text { Routine }\end{array}$ & \# SMS Probes & \% SMS Probes \\
\hline Home & 8251 & 31.0 \\
Work & 6942 & 26.0 \\
Other & 11460 & 43.0 \\
\hline
\end{tabular}

Also of critical note is whether we managed to probe our participants at varying time periods and during different activities and locations. As described previously, we used a contextual ESM to send a maximum of three SMS probes to participants each day. Our approach utilized details of the participants' daily routines in order to probe them in a nonintrusive manner and across a range of situations. Participants were free to specify blackout times - that is, time periods during each day when they did not want to be disturbed or certain locations and/or activities were they did not want to receive an SMS. Even after allowing participants to specify blackout periods, we found that we were permitted to send SMS probes to each participant during an average of 11 hours each day (min: 0, max: 24, SD: 4.9).

Table III shows the percentage of SMS probes according to usual location, where usual location is extracted from the participants' daily routines and thus reflects where participants indicated they normally are at these times or days. Approximately 30\% of SMS probes were sent when users specified that they were usually at home, $25 \%$ of probes were sent when participants specified that they were usually at work, and the remaining SMS probes $(>40 \%)$ were sent when participants specified that they were usually in other locations or participating in other activities. These locations or activities include travel/commuting, family time, socializing/going out, school/college, gym, restaurants, and so forth. Whereas the actual diary entries completed by our participants will reflect their actual location at the time they encountered their information need, these results highlight that our algorithm was at least able to successfully probe our participants in diverse situations and locations. Finally, Figure 3 illustrates the percentage of SMS probes sent along with the percentage of SMS snippets captured by time of day. This figure highlights that both probing and snippet capture occurred at varying times throughout each day with limited probes and limited snippets sent or captured in the middle of the night.

Of the 11,507 SMS snippets captured, we found that 9,579 (83.2\%) had an associated diary entry. These diary entries were generated by 93 users, resulting in an average of 103 diary entries per person (min: 1, max: 365, SD: 93.2). Thus, this showed that we had high diary entry response rates in our study.

Overall, we believe that this quantitative analysis of the SMS probes, SMS snippets, and associated diary entries shows that our study succeeded in high response rates and 


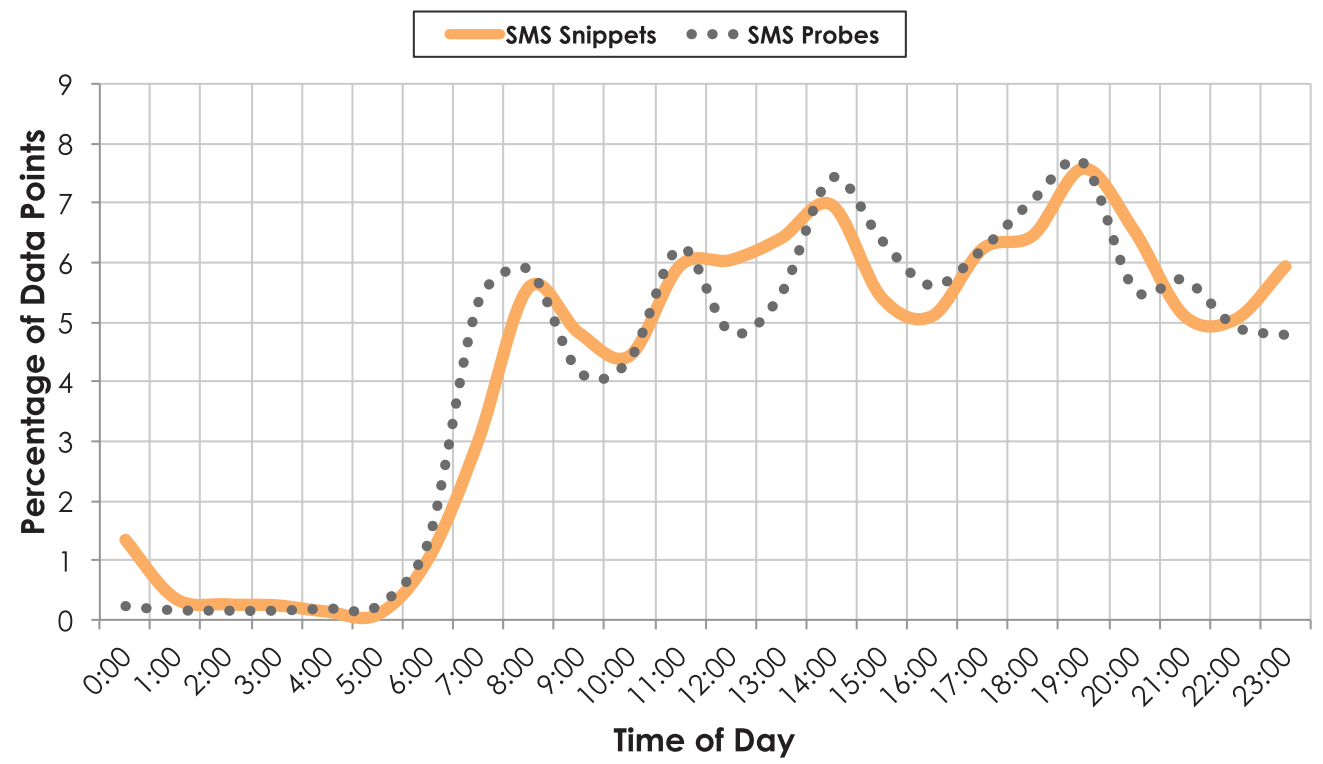

Fig. 3. The percentage of SMS probes and SMS snippets sent or captured by time of day.

that we managed to probe our participants in a diverse range of locations and at varying times each day. Although all study methodologies are subject to some drawbacks, we are confident that the dataset described in this article is varied and rich and that great care was taken not to introduce bias when probing participants and gathering data on users' information needs. In the following sections, we present our characterization of daily information needs and behaviors. Note that in these sections, we focus our analysis on the 9,579 completed diary entries submitted by participants.

\subsection{Where and With Whom Information Needs Arose}

In terms of location, we find that the majority of information needs occurred at home (43.1\%), followed by work (22.9\%) and then commuting (16.6\%). Of the remaining $17.5 \%$ of information needs, $11 \%$ occurred when the participant was out and about or in other mobile contexts like eating out, shopping, running errands, engaging in sports, attending events, and being on vacations. This implies that in $66 \%$ of cases, participants were in very familiar nonmobile contexts when their information needs arose. Compared to previous work, we find much lower occurrences of information needs arising in mobile-specific contexts. For example, Church and Smyth [2009] found that more than $67 \%$ of diary entries were generated when the user was mobile. In terms of social context-that is, who the participant was with at the time the information need arose-we find that $37.3 \%$ of entries were generated when the participant was alone. This is followed by family, with $22.6 \%$ of entries. Participants reported more information needs while in the presence of colleagues (18.6\%) than with their partners $(10.5 \%)$ or friends $(7.1 \%)$.

\subsection{Classifying Information Needs}

As discussed in Section 2, we reviewed and analyzed all related work in this space that revealed a lack of a consistent taxonomy of information needs in the literature. Some past work has focused solely on mobile information needs, and other past work has focused on information needs encountered in nonmobile settings. Although the 
topical lists of information needs generated by these prior works overlap in some regard, we find mismatching and omitted categories across the studies. See Table I for a comparison of the taxonomies presented in past related work.

After careful review, we were drawn to the information need taxonomy proposed by Dearman et al. [2008] as our starting point. The Dearman et al. taxonomy was created based on an analysis of daily information needs generated in both mobile and nonmobile settings, and as such, Dearman et al.'s study is most similar to the overall aim of our study. The Dearman et al. taxonomy covers a wide range of macro- and microcategories and is very well organized and well explained. Furthermore, it has the biggest overlap with the other classification schemes proposed by other researchers [Sohn et al. 2008; Church and Smyth 2009; Heimonen 2009]. Hence, Dearman et al.'s taxonomy provided an excellent starting point for our classification of information needs.

Our taxonomy was generated through an inductive analysis, carried out by the authors along with two hired specialists, over a subset of the diary entries. When a diary entry was assigned to a category that did not fit within the original Dearman et al. [2008] classification scheme, potential alternative categories were discussed in depth, and if a consensus was reached, a new category was created. The final category structure emerged after an iterative process and in-depth discussions between all authors of this article and the two hired specialists. It includes 9 macrocategories and 30 microcategories in total. No new macrocategories were identified compared to the original Dearman et al. [2008] classification scheme. However, we did identify 9 new microcategories.

Once the final category structure was in place, we began classifying the dataset. Diary entries were independently coded by the two hired specialists, and Cohen's kappa was used to measure intercoder reliability. We chose a coefficient of 0.9 as our minimum acceptable level of reliability between our two coders. After two iterations of independently coding a total of 1,580 SMS messages and associated information needs, discussing and resolving conflicts to increase reliability, the two hired specialists coded a third sample of 500 SMS messages and achieved a Cohen's kappa of 0.962 . The remaining dataset was then divided, and each coder independently coded his or her part of the dataset. ${ }^{3}$

Table IV shows our resulting information need taxonomy, the volume and percentage of diary entries associated with each category, descriptions of the categories, and actual examples of information needs from our user study. The table also shows a direct comparison with the Dearman et al. [2008] taxonomy. Categories that have been renamed are highlighted with an asterisk (*), whereas new microcategories are identified with a plus sign $(+)$. Note that only macro-level category details are provided in Dearman et al. [2008]; therefore, we are unable to make concrete comparisons at a microcategory level.

Before describing the categories of information needs, there are two important points to make. First, even with our comprehensive classification scheme, there was small subset of SMS that could not be categorized (1.2\% of entries). In these cases, the category is listed as Unknown. It must also be noted that approximately $8.2 \%$ of diary entries expressed no information need. In these cases, participants would simple send an SMS snippet responding with content such as "nothing," "no information needed," and "I don't need anything now." This highlights that instead of simply ignoring the SMS probe, most users felt compelled to at least reply even at times when they did not need any information. We believe that this phenomenon is due to the person-to-person communications capabilities enabled by SMS technology that formed the basis of our

\footnotetext{
${ }^{3}$ Regular meetings and discussions were held throughout this final phase to ensure that any issues or confusion about how to classify a given SMS were solved.
} 
Table IV. Categories of Information Needs with Direct Comparison to the Macro-Categories Identified by Dearman et al. [2008]

\begin{tabular}{|c|c|c|c|c|c|}
\hline \multicolumn{4}{|c|}{ Our Current Study } & \multicolumn{2}{|c|}{ Dearman } \\
\hline Category & Description/Example & \# & $\%$ & \# & $\%$ \\
\hline 1. Persons & Information about a specific person, pet or oneself. & 1098 & 11.5 & 20 & 2.3 \\
\hline 1.1 Well-being & $\begin{array}{l}\text { "How is my friend feeling health-wise?", "How many calories did I burn } \\
\text { while running?" }\end{array}$ & 117 & 1.2 & & \\
\hline 1.2 Personal Queries & $\begin{array}{l}\text { "I need to know if I will have a good day", "Are my parents awake yet?", } \\
\text { "What has my mother prepared for dinner tonight?" }\end{array}$ & 388 & 4.1 & + & \\
\hline 1.3 State of an asset & $\begin{array}{l}\text { "I bid on an item on eBay and need to know if I won", "Why does my PC } \\
\text { suddenly shut down?", "Do I have any new email?" }\end{array}$ & 142 & 1.5 & & \\
\hline 1.4 Contact information & $\begin{array}{l}\text { "The address of a friend", "The mobile phone number of a client I have to } \\
\text { call" }\end{array}$ & 78 & 0.8 & & \\
\hline $\begin{array}{l}1.5 \text { Appointments \& } \\
\text { Action Items }\end{array}$ & $\begin{array}{l}\text { Appointments - "What time is my meeting with a friend?", "When do I have } \\
\text { to go to the doctor?" }\end{array}$ & 297 & 3.1 & + & \\
\hline & Action Items - "Buy milk for breakfast", "Purchase concert tickets" & & & & \\
\hline $\begin{array}{l}1.6 \text { Remember past } \\
\text { experiences and events }\end{array}$ & $\begin{array}{l}\text { "Where did I leave my work ID?", "Did I leave the lights on in the car after I } \\
\text { parked today?", "Did I take my pills?" }\end{array}$ & 76 & 0.8 & + & \\
\hline $\begin{array}{l}\text { 2. Establishments \& } \\
\text { Organizations }\end{array}$ & $\begin{array}{l}\text { Information about a specific business, association, society, civil } \\
\text { department, organization, etc. }\end{array}$ & 541 & 5.6 & 73 & 8.5 \\
\hline 2.1 Properties & $\begin{array}{l}\text { "I need information about my company to prepare a press release", "R\&D } \\
\text { investment information of TelMex" }\end{array}$ & 101 & 1.1 & & \\
\hline $\begin{array}{l}2.2 \text { Operating } \\
\text { procedures \& Laws }\end{array}$ & $\begin{array}{l}\text { "When does the check-in of BA (British Airways) open?", "How do I get } \\
\text { travel club points through Movistar?" }\end{array}$ & 217 & 2.3 & & \\
\hline 2.3 Contact information & "The phone number for Telepizza", "I need to find the email of a supplier" & 223 & 2.3 & & \\
\hline 3. Offerings & $\begin{array}{l}\text { Information about a specific product or service provided by a single } \\
\text { establishment or organization. }\end{array}$ & 638 & 6.7 & 65 & 7.6 \\
\hline 3.1 Properties \& Quality & $\begin{array}{l}\text { "What internal memory does the Galaxy } 3 \text { smartphone have?", "How } \\
\text { much fat is in a Ferrero Rocher?" }\end{array}$ & 218 & 2.3 & * & \\
\hline 3.2 Pricing & "The price of a secondhand MacBook Pro", "Information on iPhone tari & 314 & 3.3 & & \\
\hline 3.3 Catalogue / Menu & $\begin{array}{l}\text { "List of IKEA products - folding chairs", "Menu of the day in my usual } \\
\text { restaurant" }\end{array}$ & 106 & 1.1 & + & \\
\hline 4. Events & $\begin{array}{l}\text { Information about a specific activity, function or event (in particular } \\
\text { meetings) of importance that involve people }\end{array}$ & 486 & 5.1 & 40 & 4.7 \\
\hline $\begin{array}{l}4.1 \text { Logistic \& Work } \\
\text { agendas }\end{array}$ & $\begin{array}{l}\text { "What are my meetings today?", "How many people will come to the } \\
\text { meeting?", "Information about Easter processions in Madrid" }\end{array}$ & 22 & 0.2 & & \\
\hline 4.2 Pricing & $\begin{array}{l}\text { "The entrance fee of the zoo", "The fees for public swimming pools", "How } \\
\text { much are the tickets for the game?" }\end{array}$ & 19 & 0.2 & & \\
\hline $\begin{array}{l}4.3 \text { Progress \& } \\
\text { outcomes }\end{array}$ & $\begin{array}{l}\text { "How did the stock market close today?", "Results of the handball match } \\
\text { between France and Germany" }\end{array}$ & 445 & 4.6 & & \\
\hline $\begin{array}{l}\text { 5. Environmental } \\
\text { Conditions }\end{array}$ & $\begin{array}{l}\text { Conditions of the physical environment that currently or could in the future } \\
\text { impact the inquirer. }\end{array}$ & 1088 & 11.4 & 48 & 5.6 \\
\hline 5.1 Weather & $\begin{array}{l}\text { "London weather forecast for next week", "Is it too cold outside to go } \\
\text { jogging?" }\end{array}$ & 701 & 7.3 & & \\
\hline 5.2 Traffic & "Traffic status on the M-30", "What is the traffic like?" & 387 & 4.0 & & \\
\hline 6. News \& Trivia * & $\begin{array}{l}\text { Seemingly random, inquisitive thoughts, pop culture references, news } \\
\text { items, definitions, foreign language references }\end{array}$ & 837 & 8.8 & 31 & 3.6 \\
\hline 6.1 Trivia \& Pop culture & $\begin{array}{l}\text { "The lead singer of the song we just heard?", "The highest mountain in } \\
\text { Europe?" }\end{array}$ & 368 & 3.8 & & \\
\hline 6.2 Definitions & "What does Tennis Elbow mean?", "What is zumba?" & 45 & 0.5 & + & \\
\hline 6.3 Foreign Language & "How c & 54 & 0.6 & + & \\
\hline 6.4 News & $\begin{array}{l}\text { "The most important news of the day", "General news", "Main news of the } \\
\text { world" }\end{array}$ & 370 & 3.9 & + & \\
\hline 7. Finding & $\begin{array}{l}\text { Information required to identify or locate a person, animal, } \\
\text { establishment } \& \text { organization, an offering, an event or an asset as well as } \\
\text { information related to distances and timing }\end{array}$ & 1764 & 18.4 & 300 & 35.0 \\
\hline 7.1 Name & $\begin{array}{l}\text { "The name of the street of the car workshop", "A place where I can buy } \\
\text { stationery" }\end{array}$ & 509 & 5.3 & * & \\
\hline 7.2 Locate & "Physiotherapists in Zaragoza", "Where is the street 'Ter'?" & 878 & 9.2 & & \\
\hline 7.3 Distance & $\begin{array}{l}\text { "What is the distance between Barbastro and Carcassonne in France?", } \\
\text { "The optimal route to get to work" }\end{array}$ & 157 & 1.6 & + & \\
\hline 7.4 Time & $\begin{array}{l}\text { "How long does it take from 'Puerta del Angel' to the airport with the } \\
\text { metro?", "How long will it take me to get home?" }\end{array}$ & 50 & 0.5 & + & \\
\hline 7.5 Intangibles & "Human Resources groups in Linkedln", "Find photos for a PPT" & 170 & 1.8 & + & \\
\hline 8. Availability & $\begin{array}{l}\text { Information required to identify when a person is available; an } \\
\text { organization, establishment and event (not meetings) are accessible, and } \\
\text { an offering or asset is obtainable }\end{array}$ & 1414 & 14.8 & 185 & 21.6 \\
\hline 8.1 Scheduled & "What time is the next bus?", "TV programmes today" & 1007 & 10.5 & & \\
\hline 8.2 Circumstantial & $\begin{array}{l}\text { "Will the pediatrician have an empty slot this afternoon?", "I need to know } \\
\text { if my friend is at home" }\end{array}$ & 407 & 4.2 & & \\
\hline 9. Guidance & Knowledge required to perform an action and inform a decision & 813 & 8.5 & 96 & 11.2 \\
\hline 9.1 Instruction & $\begin{array}{l}\text { "I would like to build a book case and I would like to know how", "How do I } \\
\text { install Windows 7" }\end{array}$ & 393 & 4.1 & & \\
\hline $\begin{array}{l}9.2 \text { Advice, Opinion \& } \\
\text { Recommendations }\end{array}$ & "A good movie on TV", "A place that is nice to go to eat" & 420 & 4.4 & & \\
\hline 10. Unknown & Not enough information in the diary entry to categorize the need & 114 & 1.2 & 0 & 0.0 \\
\hline 11. No Info Need & icated that they had NO information need at this time & 786 & 8.2 & 0 & 0.0 \\
\hline TOTAL & & 9579 & 100.0 & 858 & 100.0 \\
\hline
\end{tabular}

The examples are actual information needs from our study. Newly identified micro-level categories that emerged from our study are highlighted with a plus sign $(+)$, whereas categories that have been renamed from the Dearman et al. study are highlighted with an asterisk (*). 
study methodology. Next, we describe the information need categories and present key insights that emerged from this classification.

\subsection{What Types of In Situ Information Needs Arose?}

The Persons macrocategory includes information about a specific person, pet, or oneself. This category reflects needs that are highly personal in nature. We identified three new types of information needs in this category: 1.2 Personal Queries, relating to professional or personal background experiences or internal thoughts that relate to a specific person or oneself (e.g., "What has my mother prepared for dinner tonight?"), 1.5 Appointments \& Action Items, questions or thoughts concerning personal appointments that have been scheduled or actions that need to be done (e.g., "When do I have to go to the doctor"), and 1.6 Remembering Past Experiences \& Events, questions or thoughts regarding past experiences and events that are memory triggered (e.g., "Where did I leave my work ID?"). The remaining three need types in the Persons category are the same as the original Dearman et al. taxonomy-that is, 1.1 Well-Being, needs related to their mental and physical well-being (e.g., "How is my friend feeling health-wise?", 1.3 the current State of an Asset, not memory driven (e.g., "I bid on an item on eBay and need to know if I won"), and 1.4 Contact Information (e.g., "The address of a friend"). Whereas Dearman et al. [2008] found that the Persons macrocategory represented approximately $2.3 \%$ of diary entries, we find that needs of a personal nature account for a much higher percentage of our dataset (11.5\% of diary entries). However, our findings are much more in line with past work by Church and Smyth [2009], which highlights the prevalence (11\%) of what they refer to as Personal Information Management (PIM). PIM needs are private or personal to the user in question; furthermore, input from the individual is normally required to satisfy the need in question. Some examples of the needs identified by Church and Smyth of this nature include "What are my airline loyalty pin codes?" and "What have I got on today?"

Establishments \& Organizations includes information about a specific business, association, society, civil department, organization, and so forth. The three types of information needs in this category remain consistent with the original Dearman et al. taxonomy: 2.1 Properties, attributes and characteristics of the entity such as staffing, finances, physical design, and aesthetics (e.g., "R\&D investment information of TelMex"), 2.2 Operating Procedures \& Laws, the rules and regulations that govern the entities daily operating procedures (e.g., "When does the check-in of BA (British Airways) open?"), and 2.3 Contact Information of the entities (e.g., "The phone number for Telepizza"). We foundthat almost $6 \%$ of diary entries were associated with this category, with Contact Information being the most popular subcategory. This compares to $8.5 \%$ in the previous Dearman et al. study.

The Offerings macrocategory includes information about a specific product or service provided by a single establishment or organization. We identified one new microcategory of information related to offerings: 3.3 Catalogue / Menu, the list or catalogue of products or services being offered (e.g., "List of IKEA products - folding chairs"). The two additional microcategories listed are in line with the original Dearman et al. taxonomy. These are 3.1 Properties \& Quality, the physical design, makeup, attributes, quality, and affordances (e.g. "What internal memory does the Galaxy 3 smartphone have?"), and 3.2 Pricing, their cost if applicable (e.g., "Information on iPhone tariffs"). Overall, we found that $6.7 \%$ of diary entries were associated with this category of information need, with almost half of these needs relating to pricing. Dearman et al. [2008], in contrast, found that this category of needs accounted for $7.6 \%$ of information needs in their study.

Events includes information about a specific activity, function, or event of importance (particularly meetings) that involve people. This category of information need includes 
three microcategories: 4.1 Logistics \& Work Agendas, the coordination, organization, management, or operations (e.g., "How many people will come to the meeting?"), 4.2 Pricing of the event (e.g., "How much are the tickets for the game?"), and 4.3 Progress \& Outcomes, the progress, outcomes, consequences, or results of the event (e.g., "Results of the handball match between France and Germany?"). Although we did not identify any new microcategories, we did have to adapt category 4.1 to facilitate work-related events and meetings. We found that $5.1 \%$ of diary entries relate to this category, which is in line with previous findings by Dearman et al.

Environmental Conditions refers to conditions of the physical environment that impact the user, either currently or in the future. The two microcategories of Environmental Conditions include 5.1 Weather and 5.2 Traffic. Although we did not identify any new microcategories of information needs in this group, we did find almost double the volume of information needs associated with this category when compared to the Dearman et al. study ( $11.4 \%$ vs. $5.6 \%$, respectively).

We also found a much higher percentage of information needs related to News \& Trivia (8.8\% compared to $3.6 \%$ in the Dearman et al. study). This category includes seemingly random, inquisitive thoughts, pop culture references, news items, definitions, and foreign language references. We extended this category with three new microcategories: 6.2 Definitions, the meaning of a word or sentence (e.g., "What is zumba?"), 6.3 Foreign Language, translations, meanings, and pronunciation of foreign words or sentences (e.g., "How do you say ruin in English?"), and 6.4 News, general news queries and news headlines (e.g., "Main news of the world").

Information required to find the name or location of a person, animal, establishment \& organization, an offering, an event, or an asset, as well as information related to physical distances and timing is captured in the Finding category. We identified three new subcategories in the Finding category: 7.3 Distance, identifying the spatial distance from point A to point B or different ways to get to a place/destination (e.g., "The optimal route to get to work"), 7.4 Time, identifying the lapse of time from one point to another (e.g., "How long will it take me to get home?"), and 7.5 Intangibles, finding the existence of online and virtual content, or items that are intangible (e.g., "Find photos for a PPT"). The remaining microcategories in this group are in line with the original Dearman et al. classification: 7.1 Name, the name (not location) of the thing/person/organization that the person is looking for (e.g., "A place where I can buy stationery"), ${ }^{4}$ and 7.2 Locate, establishing the physical presence of a specific, already identified thing (e.g., "Where is the street 'Ter'?"). In both the Dearman et al. study and our study of daily information needs, this Finding category is the most popular category of information needs. However, Dearman et al. found a much higher proportion of these needs (35\% vs. $18.4 \%$, respectively).

Information required to identify when a person is available, an organization, establishment, and event (not meetings) are accessible, and an offering or asset is obtainable is represented by the Availability category. The two unique subcategories of availability identified by Dearman et al. remain intact: 8.1 Scheduled, availability given a defined schedule that is maintained (e.g. "What time is the next bus?"), and 8.2 Circumstantial, availability that does not follow a defined schedule or results from factors that may cause a deviation in a defined schedule (e.g., "Will the pediatrician have an empty slot this afternoon?"). Participants reported a high volume of needs relating to availability (14.8\%), with scheduled information needs being the most popular. The types of scheduled information that we found include requests for TV schedules, operating hours, and appointments. Circumstantial availability relates to the plans and

${ }^{4}$ In the case of category 7.1 , we changed the name of this microcategory to Name rather than Identify for clarity. 
intentions of a person, the ability to obtain and use an asset, and operating delays and the closure of establishments because of weather and holidays. Although this category of information need is very popular within our study, it accounts for significantly fewer diary entries than in the Dearman et al. study (14.8\% vs. $21.6 \%$, respectively).

Finally, the Guidance category encapsulates the knowledge to perform an action or to inform a decision. The two microcategories of guidance are 9.1 Instructions, instructions or directions to perform a specific task that require a series of steps (e.g., "How do I install Windows 7?"), and 9.2 Advice, Opinions, \& Recommendations from a knowledgeable source to inform the task at hand (e.g., "A good movie on TV"). Although we did not identify any new subcategories of information needs for this macrocategory when compared to Dearman et al., we did find some notable differences in the distributions: $8.5 \%$ vs. $11.2 \%$ in the Dearman et al. study.

In the following section, we explore the strategies adopted by our participants to address their information needs.

\subsection{How Are Information Needs Addressed?}

Participants were able to satisfy $61.5 \%(5,890)$ of their information needs, with $37 \%$ $(3,572)$ addressed at the time they occurred and $24 \%(2,279)$ addressed at a later point.

After reviewing the existing related literature, this time focusing on how users satisfy their information needs, we found that unlike the comprehensive information need taxonomy proposed by Dearman et al. [2008], there was no in-depth analysis of how information needs are addressed in general. The analysis and categories provided in past work are less comprehensive, with some work focusing on the use of the mobile Web to satisfy needs [Komaki et al. 2012] and others focusing on the use of mobile phones to satisfy needs [Chua et al. 2011]. Given that one of the goals of this work is to understand the relationship between types of information needs and how those needs are addressed, we needed to develop a more structured classification scheme that captures daily coping strategies. Hence, instead of using a single scheme as a starting point, we took a note of any approach mentioned in the literature and carried out an inductive analysis of a subset of the diary entries, comparing our initial list of how needs are satisfied and adding new categories or changing the category structure as needed. This inductive analysis was carried out by all of the authors of this article along with the same two hired specialists who worked on the classification of information needs. The final category structure emerged after a number of iterations of in-depth discussion and brainstorming.

Once the final category structure was in place, the diary entries were independently coded by the two hired specialists, and a Cohen's kappa coefficient of 0.9 was set as a minimum acceptable level of reliability between the two coders for this task. In this case, a single pass was needed on a sample of 500 diary entries to reach above the required Cohen's kappa value (the value obtained $=0.912$ ). After reaching the required threshold, the remaining dataset was divided, and each coder independently coded his or her dataset. ${ }^{5}$

Table V shows our resulting how information needs are addressed taxonomy, the volume and percentage of diary entries associated with each category, and actual examples from our study. We identified eight macrocategories (the majority of which have at least two microcategories), namely, Internet; Phone/TV Service; Offline Media; Asking; Books, Manuals, References; Trial \& Error or Memory; Routing Guidance; and Agendas. Whereas most of related past work in this domain has identified the use of the Internet and Asking People as a source of satisfying needs, our taxonomy highlights

\footnotetext{
${ }^{5}$ Again regular meetings and discussions were held throughout this final phase to ensure that any issues or confusion about how to classify a given diary entry were solved.
} 
Table V. Taxonomy Classification of How Information Needs Are Satisfied

\begin{tabular}{|c|c|c|c|}
\hline Category & Description/Example: Information Need and How Satisfied & \# & $\%$ \\
\hline 1. Internet & Using the internet, mobile or fixed, to address an information need & 2859 & 48.5 \\
\hline $1.1 \mathrm{App}$ & Where is the nearest pharmay - I used yellow pages mobile app & 172 & 2.9 \\
\hline 1.2 Search Engine & I used google to find webpages of restaurants in Madrid & 1324 & 22.5 \\
\hline 1.3 Specific Website & $\begin{array}{l}\text { For an update on the stock market I looked on the internet at: } \\
\text { www.bolsamania.com }\end{array}$ & 1106 & 18.8 \\
\hline 1.4 Email & I needed the URL of a blog for I looked at my email & 119 & 2.0 \\
\hline 1.5 Forums & I search a forum on Brazilian music on the Internet & 32 & 0.5 \\
\hline $1.6 \mathrm{Maps}$ & I need to find a location and found the answer in google maps & 106 & 1.8 \\
\hline 2. Phone / TV Service & $\begin{array}{l}\text { Offline service provided by a company, organization or establshment } \\
\text { that is accessed via a phone }\end{array}$ & 282 & 4.8 \\
\hline 2.1 Phone service & I needed to order a pizza so I called the pizza delivery service & 80 & 1.4 \\
\hline 2.2 SMS Service & $\begin{array}{l}\text { I needed to know the time of the next bus so I sent an SMS to the } \\
\text { mobile number associated with the bus stop }\end{array}$ & 5 & 0.1 \\
\hline 2.3 TV Electronic & When the football match is on - I look on the teletext of the TV & 197 & 3.3 \\
\hline 3. Offline Media & $\begin{array}{l}\text { Needs that are satisfied using radio, television and physical } \\
\text { newspapers }\end{array}$ & 344 & 5.8 \\
\hline 3.1 Radio & I listened to the radio on my mobile phone & 130 & 2.2 \\
\hline $3.2 \mathrm{TV}$ & I watched the news report on the TV & 136 & 2.3 \\
\hline 3.3 Newspapers & I looked at the cinema listings in the newspaper & 78 & 1.3 \\
\hline 4. Asking & Asking a person for assistance or help & 1099 & 18.7 \\
\hline 4.1 Family & I needed an electrician so I asked my cousin & 315 & 5.3 \\
\hline 4.2 Friends & I needed to find a bar and one of my friends knew a place & 222 & 3.8 \\
\hline 4.3 Colleagues & I needed to know how to contact a client so I asked my boss & 181 & 3.1 \\
\hline 4.4 Knowledgable & I asked a nurse more about diabetes & 270 & 4.6 \\
\hline 4.5 Strangers & $\begin{array}{l}\text { l asked a person in the street if they knew where I could find a } \\
\text { pharmacy }\end{array}$ & 111 & 1.9 \\
\hline $\begin{array}{l}\text { 5. Books, Manuals, } \\
\text { References }\end{array}$ & $\begin{array}{l}\text { Needs that are satisfied by referring to books, manuals, references, } \\
\text { labels on packaging or bottles, etc }\end{array}$ & 127 & 2.2 \\
\hline $\begin{array}{l}5.1 \text { Books, manuals, } \\
\text { references, physical } \\
\text { paper, labels, etc. }\end{array}$ & $\begin{array}{l}\text { I need the phone number of a pizzeria that delivers at home. I looked } \\
\text { in the directory. }\end{array}$ & 127 & 2.2 \\
\hline $\begin{array}{l}\text { 6. Trial \& Error, } \\
\text { Memory }\end{array}$ & $\begin{array}{l}\text { Trying different approaches until the problem is solved or the answer is } \\
\text { found, remembering the answer, etc. }\end{array}$ & 510 & 8.7 \\
\hline $\begin{array}{l}\text { 6.1 Trial, Error, Memory, } \\
\text { etc }\end{array}$ & $\begin{array}{l}\text { Where is my boss, I need a signature. I called the phones of all the } \\
\text { departments until I found him }\end{array}$ & 510 & 8.7 \\
\hline 7. Routing Guidance & $\begin{array}{l}\text { Satisfying information needs by following signs or instructions to reach } \\
\text { a destination }\end{array}$ & 105 & 1.8 \\
\hline 7.1 GPS/Map Routes & To find a parking spot I used the GPS application. & 55 & 0.9 \\
\hline 7.2 Signs & $\begin{array}{l}\text { Where I can get a taxi at the train station? I followed the signs in the } \\
\text { station. }\end{array}$ & 50 & 0.8 \\
\hline 8. Agendas & Satisfying information needs by looking up an agenda or schedule & 74 & 1.3 \\
\hline 8.1 Electronic / Online & When is my son's birthday? I looked up my calendar on my phone & 47 & 0.8 \\
\hline 8.2 Paper / Offline & What time is the study group today? I checked on the Post-It & 27 & 0.5 \\
\hline 9. Unknown & $\begin{array}{l}\text { The user did not specify how the need was addressed / the } \\
\text { approached listed by the user could not be classified into one of the } \\
\text { above categories }\end{array}$ & 490 & 8.3 \\
\hline TOTAL & & 5890 & 100.0 \\
\hline
\end{tabular}

Note that this analysis focuses on the subset (61.5\%) of needs that were satisfied.

other strategies used by participants. It is important to note that despite our comprehensive taxonomy, we were unable to classify approximately $8.3 \%$ of information needs (see the Unknown category). In these cases, participants avoided providing adequate details in their online diaries. 
We find that the majority of information needs were satisfied using the Internet, mobile or fixed (48.5\%). We identified six distinct microcategories within the Internet category, namely, 1.1 Apps, a native mobile application, 1.2 Search Engine (e.g., Google or Yahoo!), 1.3 Specific Web Site (or URL), 1.4 Email, 1.5 Forums, social forums where people engage and interact to help one another, and 1.6 Maps, using online maps or mapping applications to look up names or addresses of things to be located. We find that the use of search engines like Google, as well as specific Web sites/URLs, are by far the most popular use cases of satisfying information needs via the Internet $(22.5 \%$ and $18.8 \%$, respectively).

Phone/TV Service includes any needs that were addressed using an offline service provided by a company, organization, or establishment that is accessed via a phone or via the electronic guide of a TV. We identified three microcategories within this category: 2.1 Phone Service, where users call a service to satisfy their information needs (e.g., calling a directory services number), 2.2 SMS Service, where users send a text message to satisfy their information need (e.g., sending a text message to a commuter services number to get the time of the next bus or train), and 2.3 TV Electronic Guide (e.g., looking up the teletext of the TV to get the latest news, sports results, TV listings). We found that $4.8 \%$ of information needs were satisfied via this category. The Offline Media category describes needs that are addressed using 3.1 Radio (i.e., listening to the radio), 3.2 TV (i.e., watching a program on TV), ${ }^{6}$ and 3.3 Newspapers (i.e., reading the newspaper in physical form). We found that $5.8 \%$ of information needs were satisfied using offline media, with TV being the most popular means $(2.3 \%)$. Just 2.2\% of needs were satisfied using the Books, Manuals, References category. This category relates to needs addressed using physical, paper-based books, references, labels, or instructions on packaging. Examples of this category include looking up a physical Yellow Pages book to find a phone number, looking on the back of a pizza box for instructions, looking at the label on the back of a bottle to know how to use a specific product, and so forth.

The process of asking a person for assistance or help in satisfying information needs is captured by the Asking category. After the Internet category, the Asking category is the most popular means of satisfying information needs (18.7\%). We identified five microcategories of Asking, depending on whom the participants asked: 4.1 Family, 4.2 Friends, 4.3 Colleagues, people with whom the person works or studies, 4.4 Knowledgeable Source, a person thoroughly acquainted with and skilled in something through study or experience (e.g., shop assistant, lawyer, professor), and 4.5 Strangers, an unknown person/source. In the case of the Asking category, trust and relationship seem to play an important role. For example, our participants were more inclined to ask family, then friends, and then colleagues for assistance. Related past work on status message question asking has highlighted similar findings [Morris et al. 2010]. That is, people who ask questions via their online social networks had more trust in the responses provided by their friends, particularly for subjective questions-that is, looking for opinions or recommendations. In the following section, we investigate this trust dynamic in more detail and explore whether the type of information need influences whom a person asks for help. We should also point out that whereas past work has shown that people ask questions to friends and family via online social networks such as Facebook or Twitter [Morris et al. 2010], we found very few occurrences of satisfying needs via such means (only 24 occurrences from 5,890 diary entries $(<0.5 \%)$ ).

When users satisfy their needs by trying different approaches until they solve their problem or they remember the answer themselves, the needs are assigned to the Trial

${ }^{6}$ Note that the $3.2 \mathrm{TV}$ category differs from the $2.3 \mathrm{TV}$ Electronic Guide category in that needs that were satisfied by watching a program on TV are assigned in category 3.2 , whereas needs that were satisfied by viewing the teletext/electronic guide of the TV are assigned to category 2.3 . 
\& Error, Memory category. Some examples from our study include (1) a participant who needed to find the whereabouts of his boss to get a signature called the phones of all the departments of the company until he found his boss, and (2) a participant who wanted to know how to progress to the next level in a video game solved this need by simply playing the level over and over until he progressed to the next level in the game. A significant volume of information needs were satisfied in this manner (8.7\%).

Routing Guidance involves satisfying information needs by following signs or instructions to reach a specific destination. We found two unique microcategories in this group, namely, 7.1 GPS/Map Routes ${ }^{7}$ and 7.2 Signs (e.g., following highway signs, looking up information displays in airports to reach a destination, following signs and information panels in train stations). Just $1.8 \%$ of information needs were addressed using this approach.

The final category, Agendas, involves satisfying information needs by looking up an agenda or schedule. We identified two distinct microcategories to Agendas: 8.1 Electronic/Online, using electronic or online agendas and schedules (e.g., looking up the calendar on a smartphone), and 8.2 Paper/Offline, using paper-based or offline agendas or schedules (e.g., looking up a physical calendar or sticky notes with personal schedule details at home). This category was the least popular in our study, with only $1.3 \%$ of diary entries.

Although our results show that our participants employed a diverse range of modalities for satisfying their information needs, it is likely that the modality chosen to satisfy an information need is influenced by a range of factors, one of which is the type of information need in question. To date, this relationship has been largely unexplored in past work. In the following section, we investigate the relationship between the type of information needs that arise and how those needs are addressed.

\subsection{Does the Type of Information Need Influence How That Need Is Addressed?}

Figure 4 shows the relationship between the type of information need and how the need is addressed using a bubble chart. The size of the bubble in each cell depicts the popularity of that means of satisfying that specific information need type. That is, the size of the bubble corresponds to the percentage of information needs addressed by a given modality where the percentage of needs is normalized per macrocategory of information need. ${ }^{8}$ Note that we have only shown high-level macrocategories due to space constraints in the chart; however, in the following discussion, we will highlight key results related to microcategories of information needs where appropriate.

First, we find, according to the Internet category, that the Internet is a popular means of satisfying most types of information needs, although it is less popular for satisfying needs in the Persons category. As the Internet has grown in popularity and has become one of the main sources of information access, it is not surprising to see that people rely on it in their daily lives. If we look beyond the Internet category of satisfying needs, we identify some patterns. For example, whereas Phone/TV Service was not used often by our participants to satisfy their needs, it was generally used to address needs related to Events (mostly for Progress and Outcomes and Availability (mostly Scheduled items such as bus times, etc). Offline Media (e.g., radio, TV, newspapers) was a popular means of satisfying needs related to Environment (i.e., weather, traffic), Events (mostly for Progress and Outcomes), and News \& Trivia (this relates primarily to News items $(93 \%)$ ).

\footnotetext{
${ }^{7 \text { Category }}$ 7.1 GPS / Map Routes differs from category 1.6 Maps. In 7.1, the mapping service or GPS service is used to discover routing information with the intent to reach a specific destination.

${ }^{8}$ Given that some information needs were more prevalent than others, we have normalized the results per macro-level information need category.
} 




ACM Transactions on Computer-Human Interaction, Vol. 21, No. 2, Article 10, Publication date: February 2014. 
Next to the Internet category, Asking was the next most popular means of satisfying information needs in this study. If we take a closer look, we find that asking someone is a very popular means of addressing information needs in the Persons macrocategory, specifically queries related to well-being and personal queries. We also find that a significant percentage of Persons needs are satisfied using the Trial \& Error, Memory approach. Again, most relate to personal queries (50\%). If you recall, information needs categorized in the Persons macrocategory relate to people, and many are intimate in nature. Personal queries tend to relate to internal thoughts about a specific person or oneself. Given the nature of these needs, it makes sense that many times these needs can only be addressed by either (1) asking another person or (2) remembering themselves, rather than relying on a service.

In addition, what is not shown in Figure 4 is that trust or closeness to the individual appears to play a role in terms of whom to ask for help in certain situations. For example, we find that in the case of personal queries, participants asked family (49\%) or friends (27\%) most of the time. The Asking category is also very popular when addressing needs associated with Finding (especially Locate-type needs), Availability (particularly Circumstantial availability), and Guidance (specifically, Advice, Opinions, \& Recommendations). When users asked someone to help them satisfy Locate needs, we found that they asked a stranger (40\%) most of the time. When we investigated this in more detail, we found that in more than $80 \%$ of these cases, the participant was in a mobile or unfamiliar setting (i.e., commuting, walking, in the street, in a bar). In such cases, it is likely that a stranger was the only person available to help. Overall, these results highlight that although the Internet is the most popular means of addressing most daily information needs, certain types of information needs are typically satisfied by other non-Internet means. Some of these occurrences are likely to have emerged because of the availability or unavailability of certain tools at the time the information needs arose (e.g., asking a stranger for directions because you are in an unfamiliar place and do not have access to other tools); however, there appears to be a relationship between some needs and how they are satisfied (e.g., using offline media to address needs related to news, weather, and progress of events).

Although our results to date help shed light on the characteristics of daily information needs and current coping mechanisms, they do not tell us why some needs are left unsatisfied. Therefore, in the following section, we investigate why needs are not addressed and analyze the relationship between the type of information need and its probability of being satisfied.

\subsection{Why Needs Are Not Addressed}

In $38.5 \%$ of cases $(3,689)$, participants were unable to address the need at the time, and they did not go back to address this need at a later stage. In this section, we try to understand why these needs were left unaddressed. Table VI lists the reasons why needs are not satisfied (as expressed by our participants for the subset of information needs that they could not address). The majority of unsatisfied needs were left unaddressed due to insufficient time/being busy with other things (24.9\%) or because the need was not that important (15\%). Some needs were unsatisfied due to technology factors such as no Internet access (10.4\%) as well as having no coverage or no battery (almost 1\%). The Other category of unsatisfied needs (4.3\%) primarily includes reasons related to availability-for example, needing to visit physical places that were closed (i.e., shops, supermarkets) or needing to ask a person who was unavailable at the time of the need.

The table also highlights that certain needs might to be more difficult or challenging to answer than others. For example, in $30 \%$ of cases, participants indicated that they either (1) did not know how to respond to the need in question (27.3\%) or (2) could not find the information they were looking for (2.7\%). In the case of not being able to 
Table VI. Reasons Provided by Participants as to Why Their Information Needs Were Not Addressed

\begin{tabular}{lc}
\hline Why needs were left unaddressed & \% entries \\
\hline I did not know how to respond to the need & 27.3 \\
Insufficient time/busy with other things & 24.9 \\
The need was not that important & 15.0 \\
I had no internet access & 11.8 \\
I don't remember & 10.4 \\
Other & 4.3 \\
I couldn't find the information I was looking for & 2.7 \\
I was driving & 2.7 \\
Coverage, speed, or battery issues & 0.9 \\
TOTAL & 100 \\
\hline
\end{tabular}

find the information they were looking for, we found that in these cases, participants looked, searched, and often asked others but could not find the right information due to insufficient/unclear details, mistrust in the source of the information, information overload (i.e., having too much information to sift through), or because the information simply did not exist.

In order to investigate what types of information needs are most difficult for our participants to address, we analyzed the percentage of satisfied needs per information need type (Figure 5). We find that some information needs have higher failure rates than others. For example, more than $50 \%$ of needs related to Advice, Opinions, \& Recommendations, the Time it takes to get to a place, the Catalogue/Menu of a business offering, and Circumstantial availability were addressed. Likewise, Traffic-related information needs have very low success rates in terms of whether our participants were able to address such needs $(<40 \%)$. These initial results imply that there is a lack of tools for certain information need types, particularly for handling circumstantial/serendipitous meetings, for facilitating better recommendation services, and for getting advice as well as tools to help predict or inform users about traffic and timing information.

Although we have highlighted that certain information needs have lower success rates when compared to others, it it likely that contextual and demographic factors also influence people's daily information needs. In the following sections, we investigate whether contextual and demographic factors such as gender, mobile phone type, and location play a role in terms of the information needs that arise, if these needs were successfully addressed, and how these needs are addressed.

\subsection{The Impact of Gender, Mobile Phone Type, and Location on Daily Information Needs}

Past work has shown how contextual factors, such as the users' physical location and their social interactions have an impact on the information needs that arise and the means by which users attempt to address those needs [Dearman et al. 2008; Heimonen 2009]. However, to our best knowledge, demographic factors such as gender and technological factors such as mobile phone type have not been investigated.

In this section, we explore the role of gender, location, and mobile phone type (smartphone vs. feature phone $)^{9}$ on daily information needs, providing new insights into how these factors influence the types of daily information needs that people encounter and the strategies used to address them. We confirm past findings with statistical evidence showing that location has a significant impact on the daily information needs of users.

\footnotetext{
${ }^{9}$ Note that in our analysis of phone type, we are exploring differences between daily needs and how needs are addressed by users of smartphones versus feature phones.
} 


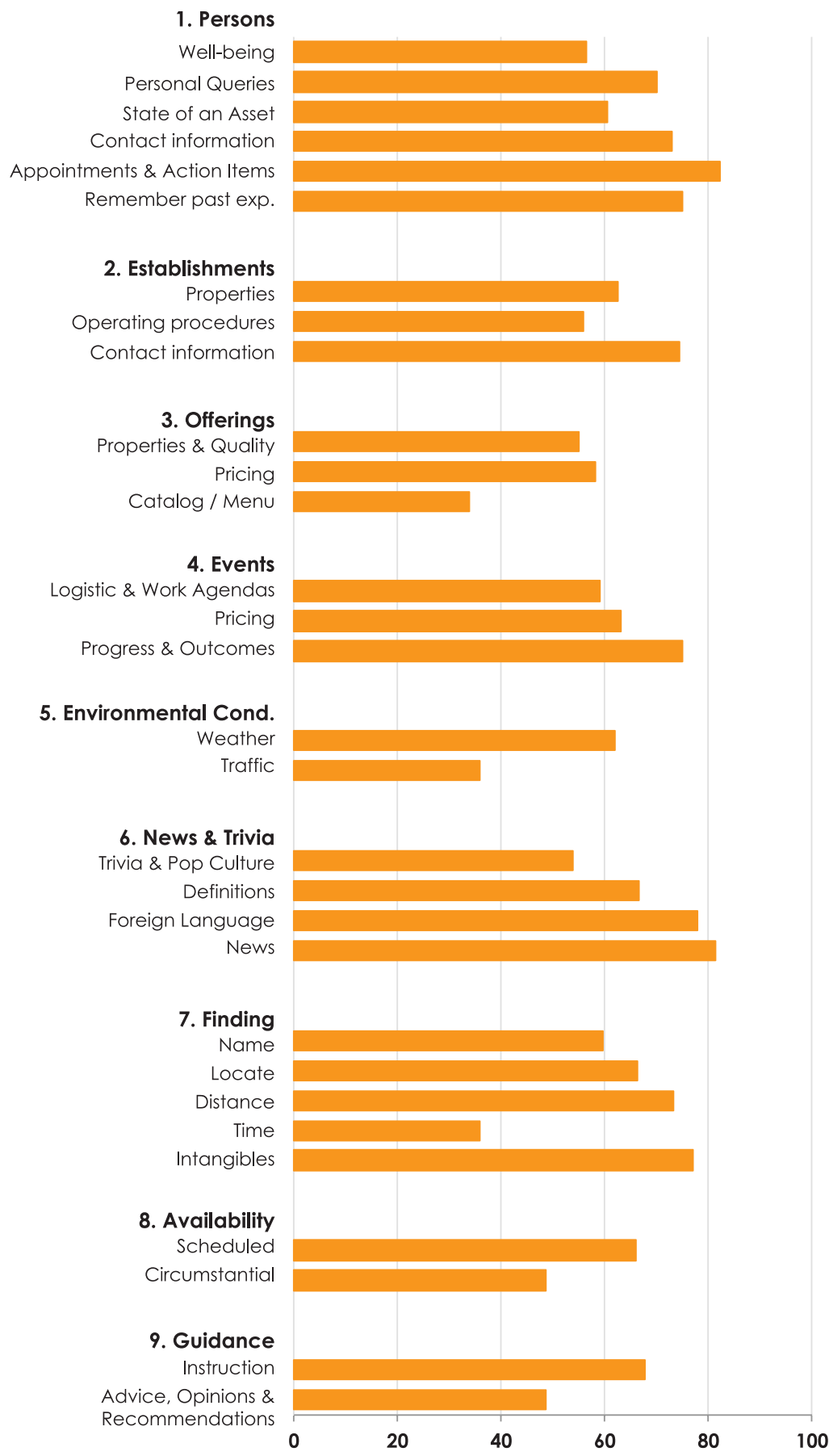

Fig. 5. Percentage of satisfied needs for each information need type. 
Table VII. Descriptive Statistics for Each Factor: Gender, Phone, and Location

\begin{tabular}{ll|cc|cc|cc|ccc}
\hline Factor & & \# Num & $\%$ & \# SMS & \% & \# Needs & $\%$ & \# Satisfied & $\begin{array}{c}\text { \% } \\
\text { Success } \\
\text { Rates \% }\end{array}$ \\
\hline Gender & Males & 66 & 61.1 & 6534 & 56.8 & 5231 & 54.6 & 3234 & 54.9 & 61.8 \\
& Females & 42 & 38.9 & 4973 & 43.2 & 4348 & 45.4 & 2656 & 45.1 & 61.1 \\
\hline Phone & Smartphone & 56 & 51.9 & 5146 & 44.7 & 4050 & 42.3 & 2595 & 44.1 & 64.1 \\
& Feature phone & 52 & 48.1 & 6361 & 55.3 & 5529 & 57.7 & 3295 & 55.9 & 59.6 \\
\hline Location & Mobile & NA & NA & NA & NA & 2690 & 28.1 & 1373 & 23.3 & 51.0 \\
& Nonmobile & NA & NA & NA & NA & 6715 & 70.1 & 4474 & 76.0 & 66.6 \\
\hline
\end{tabular}

Furthermore, we show how gender and phone type play a key role in information needs and how they are satisfied.

4.7.1. General Approach and Statistical Method. Table VII presents descriptive statistics for each of the factors that we are going to analyze, namely, gender, mobile phone type, and location. Within each of these factors, we have two groups. Given that we did not have even splits between groups in each factor-in terms of gender we had more males than females, and in terms of location we had higher volume of needs in nonmobile versus mobile settings, and so forth-any analyses that we conduct for a given factor could potentially be skewed. To avoid potential biases and to allow for a fair comparison, we present normalized percentages. For example, if we take the factor gender, we count the total number of needs per information need category for a given gender and divide this by the total number of information needs generated by that gender group. This initial analysis allows us to explore which categories of information needs and which means of satisfying those needs are more prevalent among certain groups.

In order to study the influence of each factor in depth and to determine if the observed differences are statistically significant, we conducted a series of multinomial logistic regression ${ }^{10}$ analyses. Multinomial logistic regression is used to describe, test, and predict relationships between a categorical dependent variable (in our case, information need categories or how satisfied categories) and one or more independent variables (in our case, gender, phone type, and location). Independent variables can be dichotomous (e.g., binary) or continuous (e.g., interval or ratio). Multinomial logistic regression extends binary logistic regression and allows for more than two categories of the dependent variable. Similar to binary logistic regression, multinomial logistic regression requires a reference category and evaluates the probability of categorical membership based on maximum likelihood estimation. Using this approach, we are able to determine which factors are key predictors of (1) people's daily information needs and (2) the modalities used to address those needs. We are also able to determine any statistically significant effect of each factor on specific categories of information needs or how satisfied modalities.

4.7.2. What Types of Information Needs Are Encountered by Males versus Females? Figure 6 shows the normalized percentage of information needs belonging to a specific microcategory per gender. We find notable differences between the two groups. For example, in our data, women report $2 \mathrm{x}$ more needs related to personal queries, remembering past experiences, and circumstantial availability. They also report higher volumes of needs in the Guidance macrocategory. Conversely, men report more than 4 times the volume of needs related to progress and outcomes of events when compared to women and almost $3 \mathrm{x}$ the volume of needs related to news. Needs related to weather and traffic also appear to be more popular among males in our study.

In order to assess the significance of these observations, we conducted a multinomial logistic regression analysis. For this analysis, the dependent variable was the set of 29

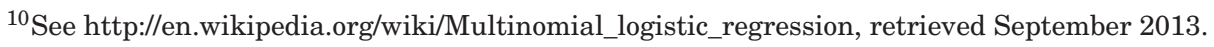




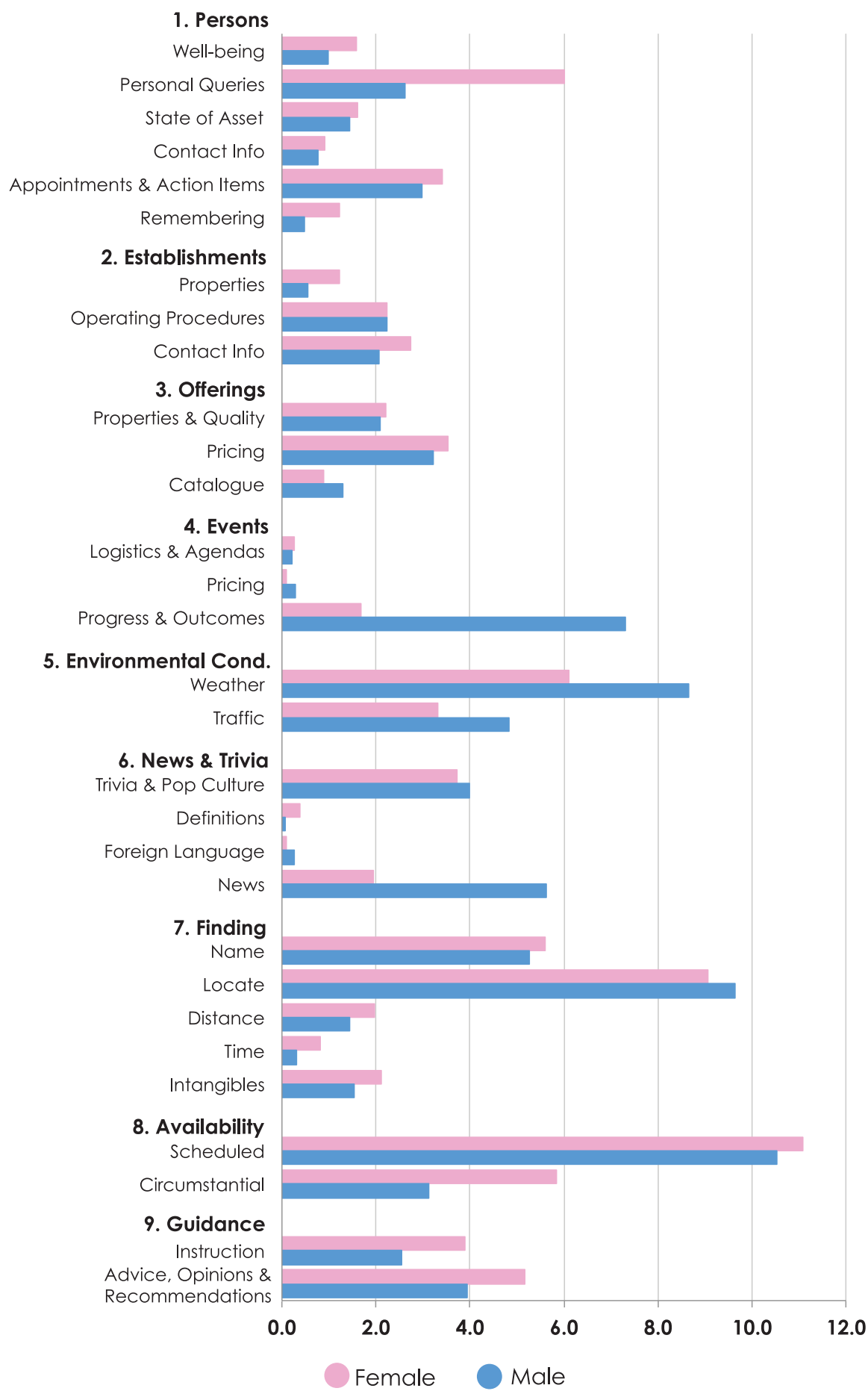

Fig. 6. Information needs by gender. The $x$ axis shows the percentage of information needs associated with each microcategory per gender. These percentages are normalized per gender group. 
Table VIII. Multinomial Logistic Regression Exploring Information Need x Gender

\begin{tabular}{|c|c|c|c|c|c|c|c|c|c|c|}
\hline \multirow{2}{*}{ Information Need } & & & \multirow[b]{2}{*}{ B } & \multirow[b]{2}{*}{ Std. Error } & \multirow[b]{2}{*}{ Wald } & \multirow[b]{2}{*}{ df } & \multirow[b]{2}{*}{ Sig. } & \multirow[b]{2}{*}{$\operatorname{Exp}(B)$} & \multicolumn{2}{|c|}{$95 \%$ Confidence } \\
\hline & & & & & & & & & Lower & Upper \\
\hline \multirow[t]{6}{*}{ 1. Persons } & 1.1 & Well-being & 0.434 & 0.197 & 4.838 & 1 & 0.028 & 1.543 & 1.048 & 2.272 \\
\hline & 1.2 & Personal Queries & 0.781 & 0.124 & 39.603 & 1 & 0.000 & 2.183 & 1.712 & 2.784 \\
\hline & 1.3 & State of an asset & 0.057 & 0.179 & 0.1 & 1 & 0.752 & 1.058 & 0.744 & 1.504 \\
\hline & & Contact information & 0.141 & 0.235 & 0.361 & 1 & 0.548 & 1.152 & 0.726 & 1.826 \\
\hline & & Appointments \& Action & 0.081 & 0.132 & 0.372 & 1 & 0.542 & 1.084 & 0.837 & 1.405 \\
\hline & $\begin{array}{l}1.6 \\
\text { expe }\end{array}$ & $\begin{array}{l}\text { Remember past } \\
\text { eriences and events }\end{array}$ & 0.914 & 0.255 & 12.886 & 1 & 0.000 & 2.495 & 1.515 & 4.111 \\
\hline \multirow{4}{*}{$\begin{array}{l}\text { 2. Establishments \& } \\
\text { Organizations }\end{array}$} & 2.1 & Properties & 0.864 & 0.221 & 15.243 & 1 & 0.000 & 2.373 & 1.538 & 3.662 \\
\hline & 2.2 & Operating procedures & & & & & & & & \\
\hline & \& La & & 0.021 & 0.15 & 0.02 & 1 & 0.887 & 1.022 & 0.761 & 1.371 \\
\hline & 2.3 & Contact information & 0.24 & 0.148 & 2.621 & 1 & 0.105 & 1.271 & 0.951 & 1.7 \\
\hline \multirow[t]{3}{*}{ 3. Offerings } & 3.1 & Properties \& Quality & -0.061 & 0.15 & 0.167 & 1 & 0.683 & 0.941 & 0.701 & 1.262 \\
\hline & 3.2 & Pricing & 0.039 & 0.129 & 0.092 & 1 & 0.762 & 1.04 & 0.807 & 1.34 \\
\hline & 3.3 & Catalogue / Menu & -0.441 & 0.212 & 4.314 & 1 & 0.038 & 0.644 & 0.425 & 0.975 \\
\hline \multirow[t]{3}{*}{ 4. Events } & 4.1 & Logistic \& Work & 0.141 & 0.431 & 0.107 & 1 & 0.743 & 1.152 & 0.495 & 2.681 \\
\hline & 4.2 & Pricing & -1.181 & 0.566 & 4.346 & 1 & 0.037 & 0.307 & 0.101 & 0.932 \\
\hline & 4.3 & Progress \& outcomes & -1.52 & 0.144 & 111.391 & 1 & 0.000 & 0.219 & 0.165 & 0.29 \\
\hline \multirow{2}{*}{$\begin{array}{l}\text { 5. Environmental } \\
\text { Conditions }\end{array}$} & 5.1 & Weather & -0.399 & 0.101 & 15.752 & 1 & 0.000 & 0.671 & 0.551 & 0.817 \\
\hline & 5.2 & Traffic & -0.426 & 0.123 & 11.98 & 1 & 0.001 & 0.653 & 0.513 & 0.831 \\
\hline \multirow[t]{4}{*}{ 6. News \& Trivia } & 6.1 & Trivia \& Pop culture & -0.088 & 0.122 & 0.516 & 1 & 0.472 & 0.916 & 0.72 & 1.164 \\
\hline & 6.2 & Definitions & 1.042 & 0.335 & 9.681 & 1 & 0.002 & 2.835 & 1.471 & 5.465 \\
\hline & 6.3 & Foreign Language & -1.222 & 0.344 & 12.639 & 1 & 0.000 & 0.295 & 0.15 & 0.578 \\
\hline & 6.4 & News & -1.115 & 0.14 & 63.238 & 1 & 0.000 & 0.328 & 0.249 & 0.432 \\
\hline \multirow[t]{5}{*}{ 7. Finding } & 7.1 & Name & 0.019 & 0.109 & 0.031 & 1 & 0.86 & 1.019 & 0.823 & 1.262 \\
\hline & & Locate & -0.111 & 0.093 & 1.42 & 1 & 0.233 & 0.895 & 0.746 & 1.074 \\
\hline & & Distance & 0.256 & 0.172 & 2.218 & 1 & 0.136 & 1.292 & 0.922 & 1.809 \\
\hline & 7.4 & Time & 0.895 & 0.31 & 8.353 & 1 & 0.004 & 2.447 & 1.334 & 4.491 \\
\hline & 7.5 & Intangibles & 0.283 & 0.166 & 2.891 & 1 & 0.089 & 1.327 & 0.958 & 1.838 \\
\hline 8. Availability & 8.2 & Circumstantial & 0.575 & 0.12 & 23.173 & 1 & 0.000 & 1.778 & 1.407 & 2.247 \\
\hline \multirow[t]{2}{*}{ 9. Guidance } & 9.1 & Instruction & 0.361 & 0.12 & 9.115 & 1 & 0.003 & 1.435 & 1.135 & 1.814 \\
\hline & $\begin{array}{l}9.2 \\
\operatorname{Rec}\end{array}$ & $\begin{array}{l}\text { Advice, Opinions \& } \\
\text { ommendations }\end{array}$ & 0.217 & 0.116 & 3.496 & 1 & 0.062 & 1.243 & 0.99 & 1.561 \\
\hline
\end{tabular}

The parameter estimates of the multinomial logistic regression model show the logistic coefficient (B), Error, Significance, and Confidence level for the gender predictor variable for each alternative category of information need; alternative category meaning, not the reference category. The reference category was 8.1 Scheduled Availability; in terms of gender, we coded females $=0$.

information need microcategories. The reference category for the dependent variable was 8.1 Scheduled Availability. ${ }^{11}$ Gender was used as the predictor variable with females set as 0 . The model's chi-square statistic was 526.684 with $p<.001$, thus statistically supporting the existence of a relationship between gender and information need and highlighting that gender is in fact a strong predictor of information need type.

Table VIII shows the full regression results. ${ }^{12}$ Individual information need categories for which there was a statistically significant effect of gender are marked in bold. In addition, we find that gender plays a statistically significant role in distinguishing 15 of the information need microcategories from the reference category.

Statistically significant positive effects are found for the well-being $(p<.05)$, personal queries $(p<.001)$, remembering past experiences $(p<.001)$, properties $(p<.001)$,

\footnotetext{
${ }^{11}$ It's standard procedure in multinomial logistic regression to choose the category with the highest frequency as the reference category. 8.1 Scheduled Availability was the most popular microcategory across all information needs, with 1,007 diary entries associated with it.

${ }^{12}$ Note that all results reported here should be interpreted in comparison to the reference category, which in this case is 8.1 Scheduled Availability.
} 
definitions ( $p<.01)$, time $(p<.01)$, circumstantial availability $(p<.001)$, and instructions $(p<.01)$ microcategories of needs.

Conversely, statistically significant negative effects are found for the catalogue / menu ( $p<.05)$, pricing $(p<.05)$, progress \& outcomes $(p<.001)$, weather $(p<.001)$, traffic $(p<.01)$, foreign language $(p<.001)$, and news $(p<.001)$ micro-categories of needs.

Combining these results with the percentages of needs displayed in Figure 6, we find that needs of a personal nature, needs related to serendipitous availability, and guidance-related needs in the form of instructions are more popular among females and for these types of needs, gender is a statistically significant predictor. Needs related to events, environmental conditions, and news are more popular among males and for these three types of needs, gender is also a statistically significant predictor.

While it might be difficult to fully explain these differences, it is interesting to note that these differences do in fact exist. In the following section we turn our attention to understanding differences in how men and women address their information needs.

4.7.3. How Are Information Needs Addressed by Males versus Females? In terms of gender, we found that the success rates - that is, the proportion of needs that could be addressedare the same for both males and females, approximately $61 \%$. However, our analysis revealed differences between men and women in terms of the means used to satisfy information needs. Figure 7 shows that the use of the Internet as a means of satisfying information needs in general is quite even among males and females. However, men appear to use maps 1.5x more than women, and conversely, women appear to use email more often than men (1.5x). It appears that the male group uses Offline Media more than women: radio is used $2 \mathrm{x}$ more, newspapers $3 \mathrm{x}$ more, and $T V 4 \mathrm{x}$ more. We also find differences in the use of the Asking strategy when addressing information needs. For example, our results highlight that women relied more on asking family members ( $>3 \mathrm{x}$ more). Books, Manuals, References was also used 2x more by women. Likewise, Trial \& Error, Memory was also more popular among the female group. Finally, we found that the male group reported not knowing how they satisfied their needs almost $8 \mathrm{x}$ more than females.

Again, to assess the significance of these observations, we conducted a multinomial logistic regression analysis. In this case, the dependent variable was the set of 22 how satisfied microcategories. The reference category for the dependent variable was 1.2 Search. ${ }^{13}$

Given that mobile phone type could also play a role in defining how specific needs are satisfied, we included both gender and phone type as the predictor variables, with females set as 0 and feature phones set as 0 . First, we describe significant effects of gender alone. Next, we will discuss significant effects of phone alone, followed by any significant effects of both predictor variables at the same time.

In this analysis, the probability of the model chi-square (300.553) for gender was $p<.001$, thus highlighting that gender is a strong predictor of how an information need will be satisfied. Table IX shows the full results of the analysis. We find some statistically significant differences. ${ }^{14}$

Statistically significant positive effects are found for the gender category alone in the email $(p<.05)$, forums $(p<.05)$, family $(p<0.001)$, and friends $(p<0.05)$ microcategories. Conversely, statistically significant negative effects are found in the maps $(p<.05)$ and radio $(p<.01)$ microcategories.

\footnotetext{
${ }^{13}$ It is standard procedure in multinomial logistic regression to choose the category with the highest frequency as the reference category. Category 1.2 Search was the most popular microcategory across all categories, with 1,324 needs associated with it.

${ }^{14}$ Note that all results reported here should be interpreted in comparison to the reference category, which in this case is 1.2 Search.
} 


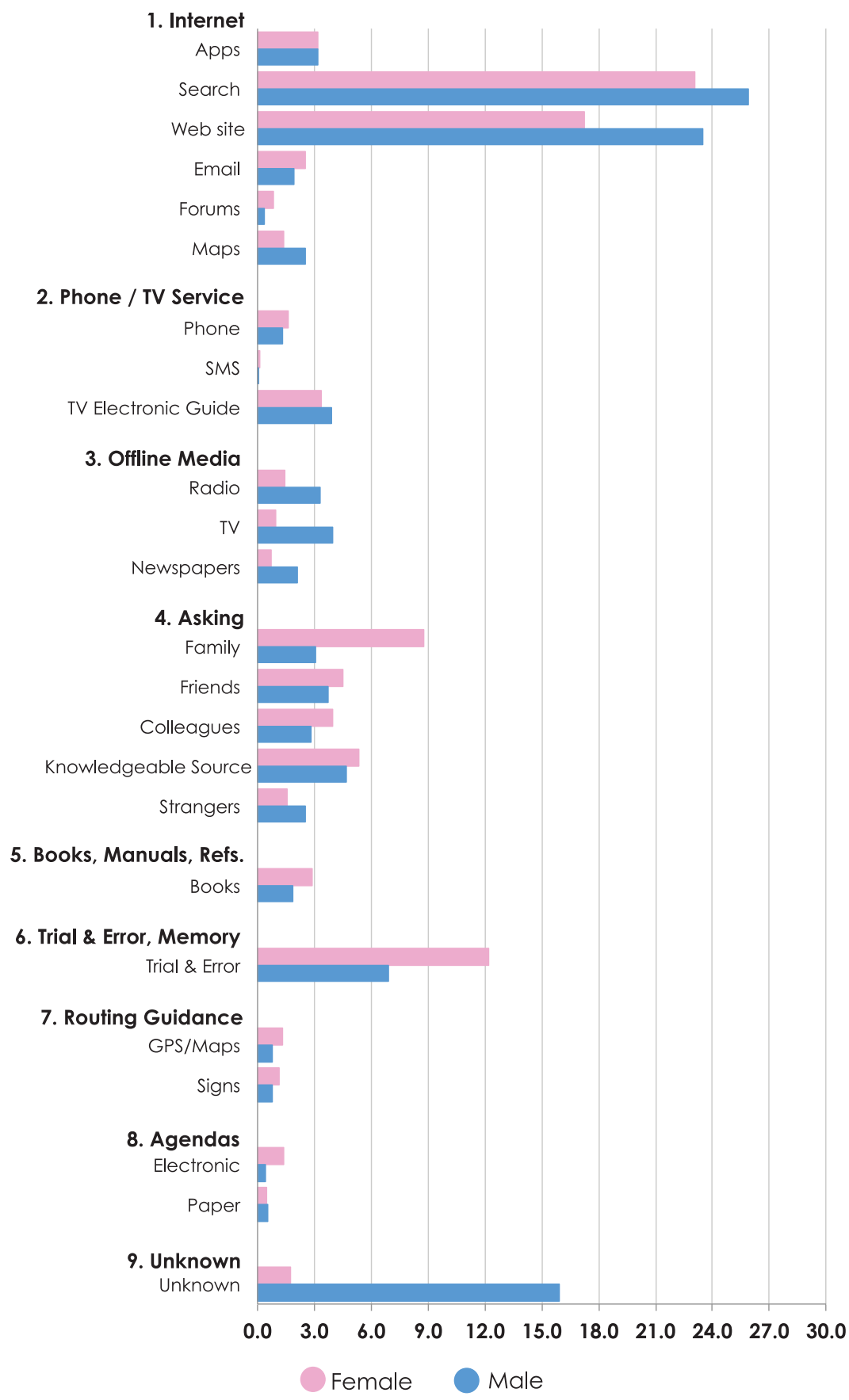

Fig. 7. How needs are addressed by gender. The $x$ axis shows the percentage of needs associated with each microcategory of how satisfied modalities per gender. These percentages are normalized per gender grouping. 
Table IX. Multinomial Logistic Regression Exploring How Needs Are Satisfied x Gender x Phone

\begin{tabular}{|c|c|c|c|c|c|c|c|c|c|c|}
\hline \multirow{2}{*}{ How Satisfied Cateogry } & & \multirow[b]{2}{*}{ Predicitors } & \multirow[b]{2}{*}{ B } & \multirow[b]{2}{*}{ Std. Error } & \multirow[b]{2}{*}{ Wald } & \multirow[b]{2}{*}{ df } & \multirow[b]{2}{*}{ Sig. } & \multirow[b]{2}{*}{$\operatorname{Exp}(B)$} & \multicolumn{2}{|c|}{$95 \%$ Confidence } \\
\hline & & & & & & & & & Lower & Upper \\
\hline \multirow[t]{10}{*}{ 1. Internet } & $1.1 \mathrm{App}$ & [gender $=0$ ] & 0.069 & 0.164 & 0.174 & 1 & 0.676 & 1.071 & 0.776 & 1.477 \\
\hline & & [phone $=0$ ] & .1 .882 & 0.198 & 90.524 & 1 & 0.000 & 0.152 & 0.103 & 0.224 \\
\hline & 1.3 Specific Web site & [gender $=0$ ] & -0.211 & 0.083 & 6.479 & 1 & 0.011 & 0.81 & 0.688 & 0.953 \\
\hline & & [phone=0] & -0.633 & 0.083 & 58.281 & 1 & 0.000 & 0.531 & 0.451 & 0.625 \\
\hline & 1.4 Email & [gender $=0$ ] & 0.406 & 0.193 & 4.444 & 1 & 0.035 & 1.501 & 1.029 & 2.189 \\
\hline & & [phone $=0$ ] & 0.21 & 0.204 & 1.064 & 1 & 0.302 & 1.234 & 0.828 & 1.838 \\
\hline & 1.5 Forums & [gender $=0$ ] & 0.955 & 0.386 & 6.13 & 1 & 0.013 & 2.598 & 1.22 & 5.53 \\
\hline & & [phone=0] & -0.621 & 0.359 & 2.986 & 1 & 0.084 & 0.538 & 0.266 & 1.087 \\
\hline & 1.6 Maps & [gender $=0$ ] & -0.489 & 0.212 & 5.292 & 1 & 0.021 & 0.613 & 0.404 & 0.93 \\
\hline & & [phone $=0$ ] & -0.227 & 0.205 & 1.226 & 1 & 0.268 & 0.797 & 0.534 & 1.191 \\
\hline \multirow[t]{4}{*}{ 2. Phone / TV Service } & 2.1 Phone service & [gender $=0$ ] & 0.336 & 0.231 & 2.114 & 1 & 0.146 & 1.399 & 0.89 & 2.201 \\
\hline & & [phone $=0$ ] & 0.164 & 0.243 & 0.455 & 1 & 0.5 & 1.178 & 0.731 & 1.898 \\
\hline & 2.3 TV Electronic Guide & [gender $=0$ ] & -0.036 & 0.154 & 0.055 & 1 & 0.814 & 0.964 & 0.714 & 1.303 \\
\hline & & [phone $=0$ ] & -0.161 & 0.156 & 1.066 & 1 & 0.302 & 0.852 & 0.628 & 1.155 \\
\hline \multirow[t]{6}{*}{ 3. Offline Media } & 3.1 Radio & [gender $=0$ ] & -0.698 & 0.201 & 12.09 & 1 & 0.001 & 0.498 & 0.336 & 0.738 \\
\hline & & [phone=0] & 0.204 & 0.196 & 1.082 & 1 & 0.298 & 1.226 & 0.835 & 1.802 \\
\hline & $3.2 \mathrm{TV}$ & [gender $=0$ ] & -1.295 & 0.228 & 32.183 & 1 & 0.000 & 0.274 & 0.175 & 0.428 \\
\hline & & [phone=0] & 0.632 & 0.211 & 9.006 & 1 & 0.003 & 1.881 & 1.245 & 2.843 \\
\hline & 3.3 Newspapers & [gender $=0$ ] & -0.964 & 0.27 & 12.77 & 1 & 0.000 & 0.382 & 0.225 & 0.647 \\
\hline & & [phone=0] & -0.49 & 0.234 & 4.38 & 1 & 0.036 & 0.613 & 0.387 & 0.969 \\
\hline \multirow[t]{10}{*}{ 4. Asking } & 4.1 Family & [gender $=0$ ] & 1.166 & 0.138 & 71.282 & 1 & 0.000 & 3.208 & 2.447 & 4.204 \\
\hline & & [phone $=0$ ] & 0.188 & 0.133 & 1.997 & 1 & 0.158 & 1.207 & 0.93 & 1.566 \\
\hline & 4.2 Friends & [gender $=0$ ] & 0.311 & 0.145 & 4.571 & 1 & 0.033 & 1.365 & 1.026 & 1.815 \\
\hline & & [phone=0] & 0.122 & 0.152 & 0.643 & 1 & 0.423 & 1.13 & 0.838 & 1.522 \\
\hline & 4.3 Colleagues & [gender $=0$ ] & 0.445 & 0.16 & 7.719 & 1 & 0.005 & 1.561 & 1.14 & 2.136 \\
\hline & & [phone=0] & -0.585 & 0.159 & 13.46 & 1 & 0.000 & 0.557 & 0.408 & 0.762 \\
\hline & 4.4 Knowledgeable Source & [gender $=0$ ] & 0.25 & 0.134 & 3.497 & 1 & 0.061 & 1.284 & 0.988 & 1.669 \\
\hline & & [phone=0] & -0.229 & 0.136 & 2.858 & 1 & 0.091 & 0.795 & 0.61 & 1.037 \\
\hline & 4.5 Strangers & [gender $=0$ ] & -0.344 & 0.204 & 2.828 & 1 & 0.093 & 0.709 & 0.475 & 1.059 \\
\hline & & [phone $=0$ ] & 0.421 & 0.219 & 3.683 & 1 & 0.055 & 1.523 & 0.991 & 2.34 \\
\hline \multirow[t]{2}{*}{ 5. Books, manuals, refs } & 5.1 Books, manuals, & [gender $=0$ ] & 0.537 & 0.189 & 8.095 & 1 & 0.004 & 1.711 & 1.182 & 2.478 \\
\hline & references, etc. & [phone =0] & -0.426 & 0.187 & 5.217 & 1 & 0.022 & 0.653 & 0.453 & 0.941 \\
\hline \multirow[t]{2}{*}{ 6. Trial, error, memory } & 6.1 Trial, Error, Memory & [gender $=0$ ] & 0.678 & 0.107 & 40.224 & 1 & 0.000 & 1.97 & 1.597 & 2.429 \\
\hline & & [phone =0] & -0.337 & 0.106 & 10.099 & 1 & 0.001 & 0.714 & 0.58 & 0.879 \\
\hline \multirow[t]{4}{*}{ 7. Routing Guidance } & 7.1 GPS/Map Routes & [gender $=0$ ] & 0.631 & 0.284 & 4.954 & 1 & 0.026 & 1.88 & 1.078 & 3.278 \\
\hline & & [phone=0] & -1.307 & 0.297 & 19.312 & 1 & 0.000 & 0.271 & 0.151 & 0.485 \\
\hline & 7.2 Signs & [gender $=0$ ] & 0.518 & 0.292 & 3.153 & 1 & 0.076 & 1.68 & 0.948 & 2.977 \\
\hline & & [phone=0] & 0.647 & 0.336 & 3.705 & 1 & 0.054 & 1.91 & 0.988 & 3.691 \\
\hline \multirow[t]{4}{*}{ 8. Agenda } & 8.1 Electronic / Online & [gender $=0$ ] & 1.336 & 0.349 & 14.632 & 1 & 0.000 & 3.806 & 1.919 & 7.548 \\
\hline & & [phone=0] & -1.245 & 0.319 & 15.279 & 1 & 0.000 & 0.288 & 0.154 & 0.537 \\
\hline & 8.2 Paper / Offline & [gender $=0$ ] & -0.06 & 0.391 & 0.024 & 1 & 0.878 & 0.942 & 0.437 & 2.028 \\
\hline & & [phone=0] & -0.744 & 0.392 & 3.606 & 1 & 0.058 & 0.475 & 0.221 & 1.024 \\
\hline
\end{tabular}

The parameter estimates of the multinomial logistic regression model show the logistic coefficient (B), Error, Significance, and confidence level for both the gender and phone predictor variables for each alternative category of information need; alternative category meaning, not the reference category. The reference category was 1.2 Search. In terms of gender, we coded females=0; in terms of phone, we coded feature phones=0. Note that the category 2.2 SMS Service was removed because of too few data points per predictor.

Combining these results with the percentages displayed in Figure 7, we find that email, forums, family, and friends are popular means of satisfying needs among females, and for these microcategories, gender is a statistically significant predictor. Maps and radio are more popular among males, and gender in this case is also a strong predictor of these microcategories, with statistical significance.

So far, we have shown significant differences in terms of how needs are satisfied focusing on gender alone. Another explanatory variable of how information needs are satisfied is technology, specifically phone type. It is likely that smartphone users satisfy their needs differently than feature phone users.

As mentioned previously, we conducted a multinomial regression including both gender and phone type as predictors. In the following section, we show that although phone type alone is not a strong predictor of how needs are addressed, phone type combined with gender leads to significant results. 
4.7.4. How Are Information Needs Addressed by Smartphone versus Feature Phone Users? Over the past 10 years, the world has witnessed huge advances in mobile handset technology. Smartphones like Apple's iPhone and Google's Android handsets are having a profound impact of how people access and consume information while on the move. There are more than 1 billion smartphone users across the globe, and with continued decreases in the pricing of these sophisticated devices, this number looks set to rise in the near future. ${ }^{15}$

Aside from larger screen sizes and advanced interaction capabilities, one of the key advantages of smartphones over feature phones is that smartphones support mobile Web access, allowing users to surf the Internet, search the Web, navigate their physical environment through interactive maps, and interact with a wealth of native mobile applications while on the go. Given these capabilities, it seems likely that there will be differences in the the means chosen to address needs by users of these device types when compared to feature phone users.

Table VII highlights that we found a total of $56(52 \%)$ smartphone users and $52(48 \%)$ feature phone users. The differential factor between these two user groups is having a mobile phone with Internet access, either via WiFi or $3 \mathrm{G}$ capabilities. In terms of mobile phone type, we found that the success rates-that is, the proportion of needs that could be addressed-are slightly higher for smartphone users at approximately $64.1 \%$ compared to $59.6 \%$ for feature phone users. This implies that perhaps having access to a wealth of information at your fingertips leads users to address more of their daily information needs.

Figure 8 highlights the popularity of various means of satisfying information needs for each mobile phone type. Overall, it appears that that the use of Offline Media, particularly $T V$ (almost $2 \mathrm{x}$ ) and Radio (almost 3x), is more popular among feature phone users. Likewise, Asking other people for help is also more popular among feature phone users, particularly family (1.5x), friends (1.5x), and strangers (2x more). Smartphone users, on the other hand, appear to use native apps (5x) and GPS/Maps (almost 3x) more often than feature phone users. They also use Agendas, particularly electronic agendas more often than feature phone users (more than $2 \mathrm{x}$ ). In order to assess the statistical significance of these observations, we conducted a multinomial regression analysis.

As described in the previous section, we used the how satisfied categories as the dependent variable and both mobile phone type and gender as the dependent variables. We found 39 men and 17 women in the smartphone user group, and 27 men and 25 women in the feature phone user group. Given that both gender and phone type are relevant factors when addressing information needs, we are interested in understanding the situations where the type of mobile phone plays a significant role in explaining how needs are satisfied versus in combination with gender.

In this analysis, the probability of the model chi-square (274.760) for phone was $p<.001$, thus highlighting that the type of phone is a strong a predictor of how an information need will be satisfied. However, if we compare this to the previous model chi-square result for gender, we find that gender provides a more significant contribution to the model. Table IX shows the results of the multinomial logistic regression.

We only find a statistically significant negative effect for the phone type alone in the app $(p<.001)$ microcategory. This result, combined with the percentages depicted in Figure 8, indicates that smartphone users are more likely than feature phone users to address their information needs via a mobile app, and only for this strategy is phone type alone a statistically significant predictor.

\footnotetext{
${ }^{15}$ Global mobile statistics 2013. See http://mobithinking.com/mobile-marketing-tools/latest-mobile-stats, retrieved January 2014.
} 


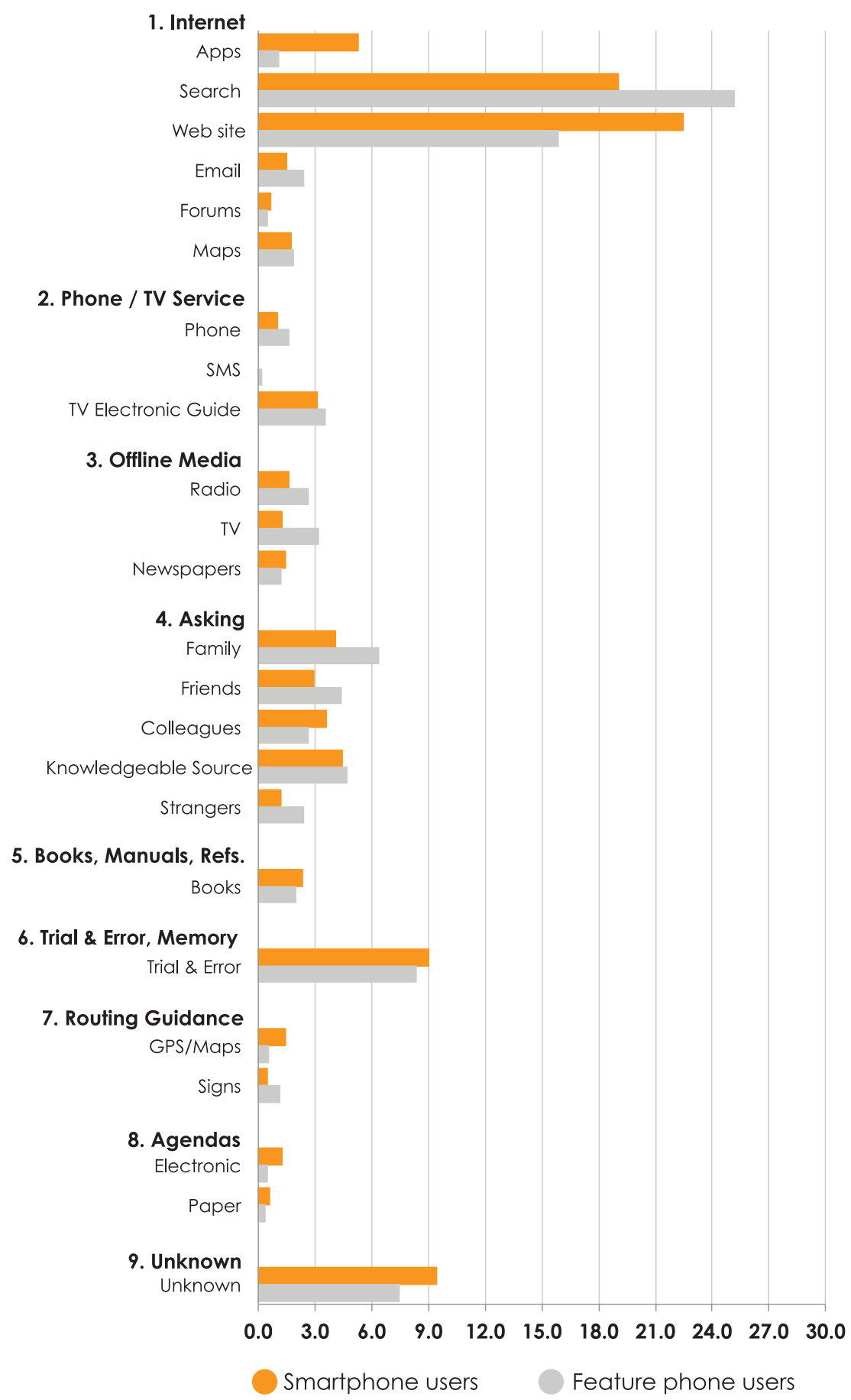

Fig. 8. How needs are addressed by mobile phone type. The $x$ axis shows the percentage of needs associated with each microcategory of how satisfied modalities per mobile phone type. These percentages are normalized per mobile phone group. 
In the remaining cases where phone has a significant effect on how needs are addressed, there is a clear impact of gender as well. That is, using gender combined with mobile phone type is a stronger differentiator of how information needs are addressed than using either predictor variable in isolation. In particular, we find statistically significant negative effects for gender and phone in the specific Web site $(p<.05 ; p<.001)$ and newspapers $(p<.001 ; p<.05)$ microcategories; a statistically significant positive effect for gender and negative effect for phone in the colleagues $(p<.01 ; p<.001)$, books/manuals $(p<.01 ; p<.05)$, GPS/map routes $(p<.05 ; p<.001)$, trial, error, memory $(p<.001 ; p<.01)$, and electronic agendas $(p<.001 ; p<.001)$ microcategories; and a statistically significant negative effect for gender and positive effect for phone in the $T V(p<.001 ; p<.05)$ microcategory.

These results, combined with the percentages depicted in Figures 7 and 8 , reveal a few interesting phenomena. Females and feature phone users address their information needs by means of a specific Web site or newspapers fewer times than males and smartphone users, and for these means of satisfying information needs, both gender and phone type are statistically significant predictors. Conversely, females and smartphone users address their information needs consulting colleagues, books/manuals, GPS, trial/error/memory, and electronic agendas more times than males and feature phone users. In addition, in this case, both gender and phone type are statistically significant predictors of these ways to satisfy information needs. Finally, males and feature phone users address their information needs by means of TV more times than females and smartphone users, with both gender and phone type being statistically significant predictors of this means of satisfying information needs.

4.7.5. What Types of Information Needs Occur in Mobile versus Nonmobile Environments? Our study focuses on characterizing daily information needs. As mentioned previously, users were free to reply to our daily SMS probes at any time and at any location. Although we found that the majority of these information needs occurred in stationary or nonmobile settings like at home and at work (66\% of information needs), a significant portion of information needs also occurred while users were on the move or in less stationary settings. Past work has shown that contextual factors such as location have an impact on the types of needs that arise as well as the means chosen to address these information needs. In this section, we complement these earlier works by exploring the role of location on daily information needs in more depth.

To conduct this analysis, we created two groups of information needs: (1) needs generated when users are in stationary/familiar settings like home, work, and college. We refer to these as nonmobile information needs and (2) needs generated when users are in mobile/unfamiliar settings like commuting, walking, shopping, traveling, and visiting bars/restaurants. We refer to these as mobile information needs. Table VII shows some descriptive statistics. Overall, we found a total of 2,690 mobile information needs $(28.1 \%)$ and 6,715 nonmobile information needs $(70.1 \%)$. The remaining information needs, $174(1.8 \%)$, could not be classified as either mobile/nonmobile; therefore, we omit this small subset from this analysis. Again, given the higher volume of information needs in nonmobile settings, we present normalized percentages.

Figure 9 show the normalized percentage of information needs belonging to a specific microcategory per location. The graph highlights that in mobile settings, the most popular information need type is Locate, which accounts for greater than $15 \%$ of all needs generated while mobile. If you recall, these needs relate to a desire to establish or learn the physical presence of a specific (identified) thing-for example, Physiotherapists in Zaragoza. This equates to more than $2 \mathrm{x}$ as many locate information needs when compared to nonmobile contexts. Traffic-related needs are almost 3x as popular in mobile contexts. So too are needs related to circumstantial availability and progress \& outcomes of events. 




Fig. 9. Information needs by location. The $x$ axis shows the percentage of information needs associated with each microcategory per location (mobile vs. nonmobile). These percentages are normalized per location group. 
Table X. Multinomial Logistic Regression Exploring Information Need x Location

\begin{tabular}{|c|c|c|c|c|c|c|c|c|c|c|}
\hline \multirow{2}{*}{ Information Need } & & & \multirow[b]{2}{*}{ B } & \multirow[b]{2}{*}{ Std. Error } & \multirow[b]{2}{*}{ Wald } & \multirow[b]{2}{*}{ df } & \multirow[b]{2}{*}{ Sig. } & \multirow[b]{2}{*}{$\operatorname{Exp}(B)$} & \multicolumn{2}{|c|}{$95 \%$ Confidence } \\
\hline & & & & & & & & & Lower & Upper \\
\hline \multirow[t]{6}{*}{ 1. Persons } & 1.1 & Well-being & 0.686 & 0.26 & 6.942 & 1 & 0.008 & 1.986 & 1.192 & 3.309 \\
\hline & 1.2 & Personal Queries & 0.553 & 0.15 & 13.625 & 1 & 0.000 & 1.738 & 1.296 & 2.331 \\
\hline & & State of an asset & 0.231 & 0.211 & 1.2 & 1 & 0.273 & 1.26 & 0.833 & 1.906 \\
\hline & & Contact information & 0.4 & 0.289 & 1.915 & 1 & 0.166 & 1.492 & 0.847 & 2.63 \\
\hline & $\begin{array}{l}1.5 \\
\text { Item }\end{array}$ & $\begin{array}{l}\text { Appointments \& Action } \\
\text { is }\end{array}$ & 0.301 & 0.157 & 3.649 & 1 & 0.056 & 1.351 & 0.992 & 1.838 \\
\hline & $\begin{array}{l}1.6 \\
\exp \end{array}$ & $\begin{array}{l}\text { Remember past } \\
\text { eriences and events }\end{array}$ & 0.29 & 0.284 & 1.041 & 1 & 0.308 & 1.336 & 0.766 & 2.332 \\
\hline \multirow{3}{*}{$\begin{array}{l}\text { 2. Establishments \& } \\
\text { Organizations }\end{array}$} & 2.1 & Properties & 0.872 & 0.296 & 8.659 & 1 & 0.003 & 2.393 & 1.338 & 4.278 \\
\hline & $\begin{array}{l}2.2 \\
\text { Law }\end{array}$ & $\begin{array}{l}\text { Operating procedures \& } \\
\text { s }\end{array}$ & 0.655 & 0.196 & 11.198 & 1 & 0.001 & 1.925 & 1.312 & 2.825 \\
\hline & 2.3 & Contact information & 0.199 & 0.173 & 1.332 & 1 & 0.248 & 1.221 & 0.87 & 1.712 \\
\hline \multirow[t]{3}{*}{ 3. Offerings } & 3.1 & Properties \& Quality & 0.258 & 0.176 & 2.144 & 1 & 0.143 & 1.294 & 0.917 & 1.826 \\
\hline & 3.2 & Pricing & -0.304 & 0.139 & 4.819 & 1 & 0.028 & 0.738 & 0.562 & 0.968 \\
\hline & 3.3 & Catalogue / Menu & -1.109 & 0.209 & 28.139 & 1 & 0.000 & 0.33 & 0.219 & 0.497 \\
\hline \multirow[t]{3}{*}{ 4. Events } & 4.1 & Logistic \& Work & 0.55 & 0.557 & 0.973 & 1 & 0.324 & 1.733 & 0.581 & 5.165 \\
\hline & 4.2 & Pricing & -0.415 & 0.481 & 0.746 & 1 & 0.388 & 0.66 & 0.257 & 1.694 \\
\hline & 4.3 & Progress \& outcomes & -0.416 & 0.121 & 11.817 & 1 & 0.001 & 0.66 & 0.52 & 0.836 \\
\hline \multirow{2}{*}{$\begin{array}{l}\text { 5. Environmental } \\
\text { Conditions }\end{array}$} & 5.1 & Weather & 0.419 & 0.118 & 12.682 & 1 & 0.000 & 1.521 & 1.208 & 1.916 \\
\hline & 5.2 & Traffic & -1.038 & 0.124 & 69.858 & 1 & 0.000 & 0.354 & 0.278 & 0.452 \\
\hline \multirow[t]{4}{*}{ 6. News \& Trivia } & 6.1 & Trivia \& Pop culture & 0.016 & 0.137 & 0.014 & 1 & 0.905 & 1.017 & 0.777 & 1.33 \\
\hline & 6.2 & Definitions & 1.125 & 0.48 & 5.504 & 1 & 0.019 & 3.08 & 1.203 & 7.885 \\
\hline & 6.3 & Foreign Language & 0.655 & 0.372 & 3.102 & 1 & 0.078 & 1.925 & 0.929 & 3.991 \\
\hline & 6.4 & News & 0.193 & 0.142 & 1.842 & 1 & 0.175 & 1.213 & 0.918 & 1.604 \\
\hline \multirow[t]{5}{*}{ 7. Finding } & 7.1 & Name & -0.094 & 0.12 & 0.613 & 1 & 0.434 & 0.91 & 0.72 & 1.152 \\
\hline & 7.2 & Locate & -0.888 & 0.098 & 82.156 & 1 & 0.000 & 0.412 & 0.34 & 0.499 \\
\hline & & Distance & -0.402 & 0.181 & 4.961 & 1 & 0.026 & 0.669 & 0.469 & 0.953 \\
\hline & 7.4 & Time & -0.914 & 0.294 & 9.632 & 1 & 0.002 & 0.401 & 0.225 & 0.714 \\
\hline & 7.5 & Intangibles & 1.166 & 0.259 & 20.225 & 1 & 0.000 & 3.209 & 1.93 & 5.333 \\
\hline 8. Availability & & Circumstantial & -0.675 & 0.123 & 30.254 & 1 & 0.000 & 0.509 & 0.4 & 0.647 \\
\hline \multirow[t]{2}{*}{ 9. Guidance } & 9.1 & Instruction & 1.458 & 0.198 & 54.43 & 1 & 0.000 & 4.296 & 2.916 & 6.327 \\
\hline & $\begin{array}{l}9.2 \\
\operatorname{Rec} \\
\end{array}$ & $\begin{array}{l}\text { Advice, Opinions \& } \\
\text { :ommendations }\end{array}$ & 0.26 & 0.137 & 3.629 & 1 & 0.057 & 1.297 & 0.993 & 1.695 \\
\hline
\end{tabular}

The parameter estimates of the multinomial logistic regression model show the logistic coefficient (B), Standard Error, Significance, and Confidence level for the location predictor variable for each alternative category of information need; alternative category meaning, not the reference category. The reference category was 8.1 Scheduled Availability. In terms of location, we coded nonmobile=0.

In contrast, we find that needs in the Persons macrocategory tend to be more popular in nonmobile settings, particularly needs related to personal queries (almost $2 \mathrm{x}$ ). We also find more than 1.5x weather-related needs and more than $4 \mathrm{x}$ the volume of needs related to instructions in these stationary settings.

Once again, we use regression to assess the significance of these observations. In this case, our dependent variable was the set of 29 information need microcategories. The reference category for the dependent variable was 8.1 Scheduled Availability. ${ }^{16}$ Location (mobile or nonmobile) was used as the predictor variable, with nonmobile set as 0 . In this analysis, the probability of the model chi-square (604.760) was $p<.001$, thus statistically supporting the existence of a relationship between the location and type of information need.

Table X shows the full regression results and highlights some notable differences. ${ }^{17}$ Individual information need categories for which there was a statistically significant

\footnotetext{
${ }^{16}$ It is standard procedure in multinomial logistic regression to choose the category with the highest frequency as the reference category. 8.1 Scheduled Availability was the most popular microcategory across all information needs, with 1,007 diary entries associated with it.

${ }^{17}$ Note that all results reported here should be interpreted in comparison to the reference category, which in this case is 8.1 Scheduled Availability.
} 
effect of location are marked in bold. We found that location plays a statistically significant role in distinguishing 16 of the information need microcategories.

Statistically significant positive effects are found for information needs related to properties $(p<.01)$, operating procedures \& laws $(p<.01)$, weather $(p<.001)$, wellbeing $(p<.01)$, personal queries $(p<.001)$, intangibles $(p<.001)$, definitions $(p<.05)$, and instructions $(p<.001)$.

In contrast, statistically significant negative effects are found for information needs related to progress \& outcomes of events $(p<.01)$, pricing of offerings $(p<.05)$, catalogue/menu $(p<.001)$, locate $(p<.001)$, distance $(p<.05)$, time $(p<.01)$, circumstantial availability $(p<.001)$, and traffic $(p<.001)$

If we combine these results with the percentages displayed in Figure 9, it appears that information needs tied to locations and "finding things" are significantly more likely to occur in mobile contexts. Likewise, needs related to dynamic informationthat is, information that is likely to change frequently, such as traffic reports, the availability of a person, and the time it takes to get from one point to another-are all more popular in mobile settings. Thus, our results show that location is a significant predictor of certain daily information need types.

4.7.6. How Are Information Needs Addressed in Mobile versus Nonmobile Settings? In this section, we explore differences in how information needs are addressed in mobile versus more stationary settings. In terms of location, we found that the success rates-that is, the proportion of needs that could be addressed-are higher for nonmobile information needs compared to needs that occur in mobile settings, at $66.6 \%$ compared to $51.0 \%$, respectively. This implies that users in mobile and less familiar environments have more difficulties in addressing their information needs. Figure 10 helps to investigate this finding in more detail by highlighting the differences in the strategies used to address information needs in mobile and nonmobile settings.

For example, we find that the use of Offline Media, particularly newspapers and radio (almost $4 \mathrm{x}$ and $3 \mathrm{x}$, respectively), is more popular among users in mobile settings. Likewise, we find that Asking other people for help is also more popular among users in mobile settings, with knowledgeable sources $(2 \mathrm{x})$ and friends $(2 \mathrm{x})$ being most popular. It appears that strangers are almost only asked for assistance when users are mobile. Overall, this makes sense given that family and colleagues are more likely to be found in home and work contexts and that strangers are often used as a source of knowledge in unknown or unfamiliar settings. We also find the use of Routing Guidance to be more popular for users addressing mobile information needs. For needs that occur in nonmobile settings, we find that the Internet in general is more popular, particularly search (1.5x more), a specific Web site (1.5x more), and email (3x more). Likewise, Books, Manuals, References is also more popular in stationary settings (almost 2x more).

Overall, these results highlight that certain modalities for addressing information needs are used more in mobile environments compared to nonmobile environments. That is, there appears to be a relationship between how a need is satisfied and the location in which that need arose. In order to determine if these observed differences are in fact significant and to understand the influence of location in more depth, we again conducted a multinomial regression analysis.

For this regression analysis, the dependent variable was the set of 22 how satisfied microcategories. The reference category for the dependent variable was 1.2 Search.$^{18}$ The predictor variable in this analysis was location, with nonmobile set as 0 . In this

\footnotetext{
${ }^{18}$ It is standard procedure in multinomial logistic regression to choose the category with the highest frequency as the reference category. Category 1.2 Search was the most popular microcategory across all categories, with 1,324 needs associated with it.
} 


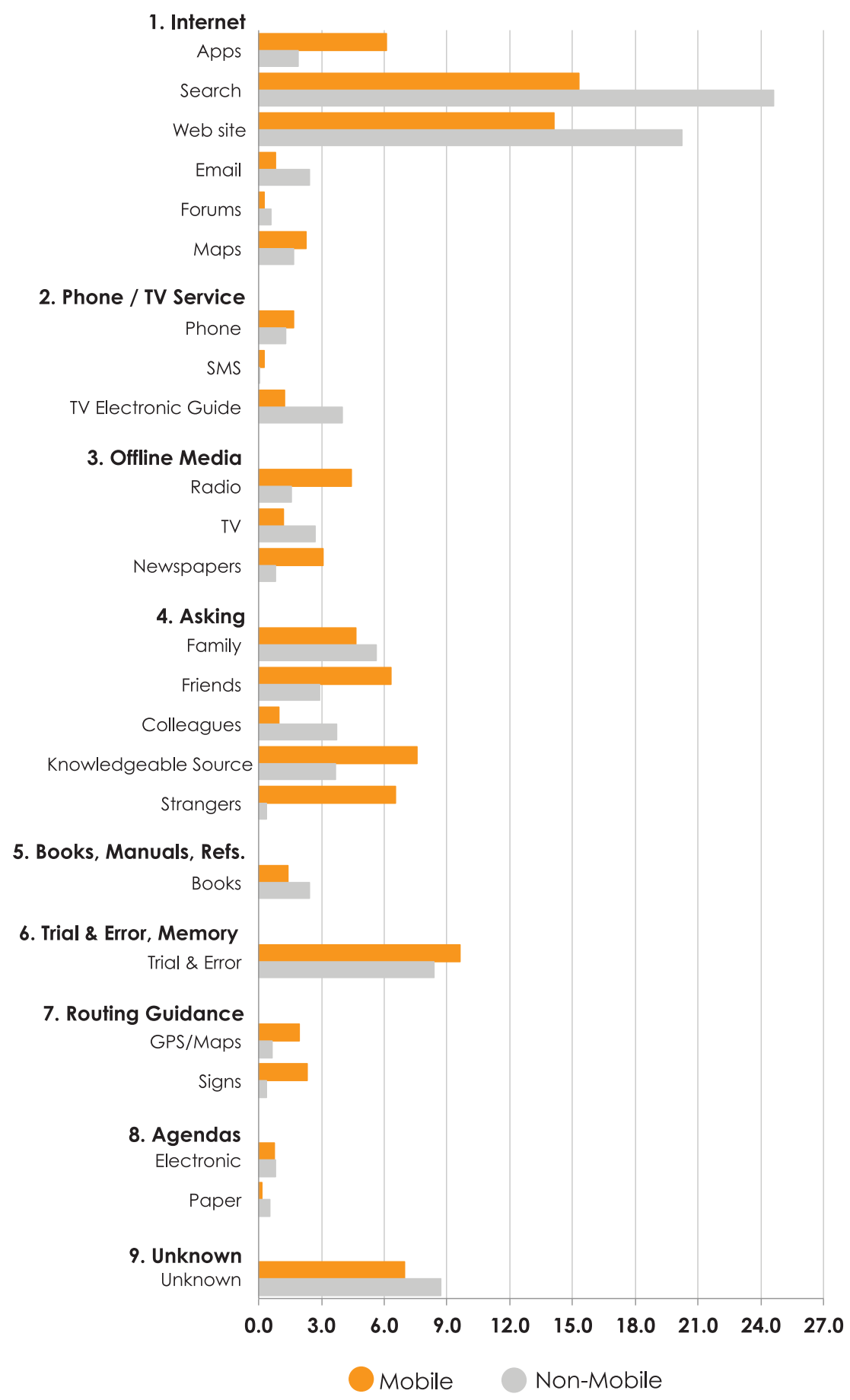

Fig. 10. How needs are addressed by location. The $x$ axis shows the percentage of needs associated satisfied with each microcategory of how satisfied modalities per location (mobile vs. nonmobile). These percentages are normalized per location group. 
Table XI. Multinomial Logistic Regression Exploring How Needs Are Satisfied x Location

\begin{tabular}{|c|c|c|c|c|c|c|c|c|c|}
\hline \multirow{2}{*}{ How Satisfied Category } & & \multirow[b]{2}{*}{ B } & \multirow[b]{2}{*}{ Std. Error } & \multirow[b]{2}{*}{ Wald } & \multirow[b]{2}{*}{ df } & \multirow[b]{2}{*}{ Sig. } & \multirow[b]{2}{*}{$\operatorname{Exp}(B)$} & \multicolumn{2}{|c|}{$95 \%$ Confidence } \\
\hline & & & & & & & & Lower & Upper \\
\hline \multirow[t]{5}{*}{ 1. Internet } & 1.1 App & -1.658 & 0.172 & 93.227 & 1 & 0.000 & 0.191 & 0.136 & 0.267 \\
\hline & 1.3 Specific Website & -0.117 & 0.109 & 1.14 & 1 & 0.286 & 0.89 & 0.718 & 1.102 \\
\hline & 1.4 Email & 0.626 & 0.325 & 3.708 & 1 & 0.054 & 1.871 & 0.989 & 3.54 \\
\hline & 1.5 Forums & 0.252 & 0.541 & 0.217 & 1 & 0.642 & 1.286 & 0.445 & 3.714 \\
\hline & 1.6 Maps & -0.774 & 0.226 & 11.695 & 1 & 0.001 & 0.461 & 0.296 & 0.719 \\
\hline \multirow[t]{3}{*}{ 2. Phone / TV Service } & 2.1 Phone service & -0.75 & 0.258 & 8.439 & 1 & 0.004 & 0.472 & 0.285 & 0.783 \\
\hline & 2.2 SMS Service & -3.044 & 1.121 & 7.38 & 1 & 0.007 & 0.048 & 0.005 & 0.428 \\
\hline & 2.3 TV Electronic Guide & 0.702 & 0.265 & 7.035 & 1 & 0.008 & 2.018 & 1.201 & 3.39 \\
\hline \multirow[t]{3}{*}{ 3. Offline Media } & 3.1 Radio & -1.535 & 0.191 & 64.418 & 1 & 0.000 & 0.216 & 0.148 & 0.314 \\
\hline & 3.2 TV & 0.357 & 0.277 & 1.667 & 1 & 0.197 & 1.429 & 0.831 & 2.458 \\
\hline & 3.3 Newspapers & -1.812 & 0.239 & 57.34 & 1 & 0.000 & 0.163 & 0.102 & 0.261 \\
\hline \multirow[t]{5}{*}{ 4. Asking } & 4.1 Family & -0.291 & 0.159 & 3.355 & 1 & 0.067 & 0.747 & 0.547 & 1.021 \\
\hline & 4.2 Friends & -1.248 & 0.157 & 62.859 & 1 & 0.000 & 0.287 & 0.211 & 0.391 \\
\hline & 4.3 Colleagues & 0.895 & 0.298 & 9.048 & 1 & 0.003 & 2.448 & 1.366 & 4.387 \\
\hline & 4.4 Knowledgable Source & -1.202 & 0.146 & 67.604 & 1 & 0.000 & 0.301 & 0.226 & 0.4 \\
\hline & 4.5 Strangers & -3.385 & 0.282 & 144.527 & 1 & 0.000 & 0.034 & 0.02 & 0.059 \\
\hline 5. Books, manuals, refs & 5.1 Books, manuals, refs & 0.08 & 0.26 & 0.095 & 1 & 0.758 & 1.083 & 0.651 & 1.803 \\
\hline 6. Trial, error, memory & 6.1 Trial, Error, Memory & -0.611 & 0.126 & 23.471 & 1 & 0.000 & 0.543 & 0.424 & 0.695 \\
\hline \multirow[t]{2}{*}{ 7. Routing Guidance } & 7.1 GPS/Map Routes & -1.621 & 0.28 & 33.524 & 1 & 0.000 & 0.198 & 0.114 & 0.342 \\
\hline & 7.2 Signs & -2.29 & 0.309 & 54.787 & 1 & 0.000 & 0.101 & 0.055 & 0.186 \\
\hline \multirow[t]{2}{*}{ 8. Agenda } & 8.1 Electronic / Online & -0.377 & 0.365 & 1.064 & 1 & 0.302 & 0.686 & 0.335 & 1.404 \\
\hline & 8.2 Paper / Offline & 0.868 & 0.739 & 1.381 & 1 & 0.24 & 2.382 & 0.56 & 10.133 \\
\hline
\end{tabular}

The parameter estimates of the multinomial logistic regression model show the logistic coefficient (B), Error, Significance, and Confidence level for the location predictor variable for each alternative category of information need; alternative category meaning, not the reference category. The reference category was 1.2 Search. In terms of location, we coded nonmobile $=0$.

analysis, the probability of the model chi-square (602.924) for location was $p<.001$, thus highlighting that overall, location is a strong predictor of how an information need will be satisfied.

Table XI shows the full results of the analysis, and we find some statistically significant differences between needs more likely to occur in mobile versus more stationary settings. ${ }^{19}$

For example, we found statistically significant negative effects for apps $(p<.001)$, native maps $(p<.01)$, GPS $(p<.001)$, signs $(p<.001)$, radio $(p<.001)$, newspapers $(p<.001)$, phone service $(p<.01)$, SMS service $(p<.01)$, and trial \& error $(p<.001)$. In terms of the Asking macrocategory, we also found statistically significant negative effects for friends $(p<.001)$, knowledgeable sources $(p<.001)$, and strangers $(p<$ .001). Conversely, we found statistically significant positive effects for TV Electronic Guide $(p<.01)$ and colleagues $(p<.01)$.

Combined with the results presented in Figure 10, it appears that mobile-specific and location-based technologies such as native apps, maps, GPS, phone services, and SMS services are more popular in mobile settings. Relying on asking friends, knowledgeable sources, and strangers, as well as using radio and newspapers, are also more popular means of satisfying information needs in mobile settings compared to nonmobile settings.

\section{DISCUSSION AND RESEARCH IMPLICATIONS}

The goal of this work was to provide a fundamental understanding of the daily information needs of people. We have presented a comprehensive taxonomy of daily information needs and the modalities chosen to address those needs. In addition, we

\footnotetext{
${ }^{19}$ Note that all results reported here should be interpreted in comparison to the reference category, which in this case is 1.2 Search.
} 
have explored the relationship between information needs, how they are satisfied, and three additional factors: demographics (gender), technological (mobile phone type), and contextual (location). We have shown how these factors influence both the needs that arise and the way in which those needs are satisfied. Overall, we have found that our daily information needs are highly varied, intricate, and dynamic. In general, people still face difficulty in finding answers to their daily questions. We believe that the realworld insights reported in this article add to a growing body of related work on people's daily information needs, and we hope that these insights can help inform the design of new services that might better serve people in addressing their daily information needs. In this section, we discuss some of these insights and highlight a number of implications that emerged from our study.

\subsection{Why Information Needs Are Addressed That Way: Intent Versus Lack of Choice?}

In Section 4.7, we explored the impact of gender, mobile phone type, and location on how information needs are addressed. We found statistically significant differences in terms of how males versus females and smartphone versus feature phone users addressed their needs. We also found significant differences in how information needs are satisfied in mobile versus nonmobile environments. For example, we found that GPS $(p<.001)$, physical signs $(p<.001)$, radio $(p<.001)$, and newspapers $(p<.001)$ are statistically more likely to be used to satisfy needs in mobile settings. When we focused on the Asking category, we found that friends $(p<.001)$, knowledgeable sources $(p<.001)$, and strangers $(p<.001)$ were relied on significantly more in mobile settings. Although these results show that differences exist in how people address their information in mobile environments, they do not tell us why certain modalities are more popular than others. From the data collected in our study, we cannot assess whether the participants preferred some modalities over others. Likewise, we do not know whether their explicit intention was to choose a certain modality in a specific setting or if the reason for using that means of addressing their information need was because it was the only means available at the time. In other words, although we have been able to find correlations between the variables, we are unable to prove any kind of causation. If we take the example of asking a stranger for help, do our participants prefer to ask strangers for help in some situations? Or are strangers the only people available to ask in some situations? Perhaps if other tools were available at the time, our participants might have chosen to use them instead.

Related to this observation is our analysis of why some needs were left unaddressed. In Section 4.6, we discussed why users found their information needs difficult to address, and we found the most popular reason was that users simply did not know how to solve the need in question. However, when we focused on mobile information needs, we find some differences in the reasons expressed by our participants. Although not knowing how to respond to the need in question is still the most popular reason (with $29 \%$ of diary responses), having no access to the Internet was also a contributing factor $(22 \%)$. We also found issues related to limited network coverage and battery problems were expressed mainly by users in mobile environments, particularly while commuting. In these situations, participants would not have been able to address their needs using their mobile phone and would have had to rely on other means.

Although beyond the scope of this work, future research should question and investigate why people choose to address their daily information needs using some means over others so that we can gain more insights into the actual intentions of people.

\subsection{Understanding Evolving Behaviors}

We found that the Internet (48.5\% of all satisfied needs), Asking people (18.7\%), and Trial \& Error (8.7\%) were the most popular means of addressing information needs. 
Furthermore, our taxonomy of how needs are satisfied highlighted that users employ a diverse range of coping mechanisms and tend to use certain means of addressing their needs in certain situations. However, it is likely that the modalities people use to address their needs will change over time, particularly as new forms of technology become available.

Our study was conducted in 2011 , at which point there were approximately $18 \%$ smartphone users globally. By 2014, this number is expected to reach $38.6 \%$, and in some countries, for example, the United States, the United Kingdom, and South Korea, the number of smartphone owners has already surpassed $50 \% .{ }^{20}$ Likewise, the number of native mobile apps is growing at a phenomenal pace. For example, in January 2011, Flurry, a company that provides app developers with tools to measure how much people are using their apps, tracked 0.1 trillion in-app events worldwide. In January 2013, this number had risen to 1.3 trillion in-app events, highlighting that people are engaging with those apps at highly increased rates. ${ }^{21}$ Advances are also being witnessed in social networking and other technology-mediated communications. For example, applications like WhatsApp and SnapChat are changing the way that people engage and communicate. ${ }^{22}$

As these and other technological advances enter our daily lives, it is likely that people will adopt and appropriate these technologies to help them address their daily information needs. Furthermore, perhaps the ability to access new types of information via these technologies might also impact on the types of needs that people express on a day-to-day basis. As such, future research should explore evolving behaviors. If we conduct a similar study in the future, what new needs might emerge? And what other modalities would be added to our "How Satisfied?" taxonomy?

\subsection{Understanding Gender Differences}

Our analysis of gender and daily information needs highlighted that significant differences exist among males and females in terms of the needs they encounter and how they satisfy those needs.

For example, we found that email, forums, family, and friends were a more popular means of satisfying information needs among females $(p<.001$ to $p<.05)$, whereas maps and radio were more popular among males $(p<.01$ to $p<.05)$. Of interest is that emails, forums, and asking people are all means of conversation, discussion, and person-to-person interaction. Thus, it appears that females in our study were more likely to rely on social approaches and communicative technologies to satisfy their needs when compared to males. For all of these microcategories, the type of mobile phone did not have a statistically significant effect.

An explanation of why such patterns were found is beyond the scope of this work; however, it does appear that gender matters more than mobile phone type in terms of how daily information needs are addressed. Future research should explore these differences in behaviors in more depth in order to shed light on what we can do to support or expand how each group addresses their daily information needs with technology.

\footnotetext{
${ }^{20}$ eMarketer. 2013. Smartphone Adoption Tips Past 50\% in Major Markets Worldwide. See http://www. emarketer.com/Article/Smartphone-Adoption-Tips-Past-50-Major-Markets-Worldwide/1009923, retrieved January 2014.

${ }^{21}$ VentureBeat. 2013. Mobile App Growth Exploding, and Shows No Signs of Letting Up. See http:// venturebeat.com/2013/07/10/state-of-the-apposphere/, retrieved January 2014.

${ }^{22}$ See http://www.pehub.com/2013/05/01/laugh-if-you-want-but-messaging-apps-going-natural/.
} 


\subsection{Understanding Differences and Similarities}

As researchers of people's experiences, behaviors, and needs, we tend to look not only for patterns in human behavior but also-and probably more importantly-for differences in these patterns over time or across different demographic groups.

Although these differences are often interesting, detecting commonalities is important because it might uncover universal patterns of behavior. In Section 4.2, we presented our classification of daily information needs. Our resulting information needs taxonomy was based on a classification scheme proposed by Dearman et al. [2008]. We identified some new categories of information needs during our analysis but also found that the majority of Dearman's original categories remained the same. The Dearman et al. study was conducted in Canada, whereas our current study was conducted in Spain. These studies are by no means generalizable to the entire world, nor can we use these insights to make broad claims about the universality of our findings. However, it would be interesting to see similar studies replicated in other countries and among other cultures to see what differences and, perhaps more interestingly, what similarities exist in terms of daily information needs. Knowing if people's daily information needs manifest themselves universally, or if individual differences are really what matter, will help inform the design of new technologies that help people satisfy these needs.

\subsection{Contextual Information Needs and Contextual Services}

In order to create novel applications and services that are easy to use, relevant to the task at hand, and provide an enriching experience to the end user, it is crucial to understand not only user behaviors and needs but also, more importantly, the contexts in which those behaviors and needs emerge. Contextual information can provide important insights into specific situations, events, and interactions. In this article, we have shown how contextual (location), technological (mobile phone type), and demographic (gender) factors influence our daily information needs and the means to satisfy those needs.

As researchers, designers, and developers take on new challenges associated with ubiquity, multiple devices, diverse information channels, and a wider audience, understanding the different types of information needs that occur in these contextual situations and the current coping strategies can help in the design of future contextual services. For example, our exploration of daily information needs in mobile environments can provide useful knowledge when designing novel location-based services. Likewise, our insights into the information needs of males versus females might help in the creation of new engaging services targeted to a specific gender group. Our hope is that the insights and discussion presented in this article enable more informed design decisions.

It is also important to note that a number of open research questions regarding information needs and context remain. For example, how do users handle urgent information needs versus more casual information desires? How does social and cultural context impact the daily information needs of people and the means used to address those needs? Although we noticed differences in gender when it comes to daily information needs, do other demographic factors also have an effect-for example, age and socioeconomic status? Does access to certain services and applications affect the success rates of information needs? These exemplary questions would be interesting to explore further in order to get an more complete understanding of our daily information needs.

\section{LIMITATIONS}

By utilizing a contextual ESM, a snippet-based diary technique using SMS, and an online Web diary to gather in situ insights, our goal was to learn about people's daily 
information needs in a naturalistic, unobtrusive manner. However, as with all study methodologies, our approach has some potential drawbacks.

First, our study was conducted in Spain, and as such there may be a cultural effect on the information needs and findings that we report. In our comparison to Dearman et al. [2008], we found that many of the categories of daily information needs hold between the studies, which perhaps hints at some recurring information need types. However, it must be pointed out that we cannot make broad claims about the universality of our findings.

Second, the very act of sampling from a person's everyday life raises on a number of issues and challenges [Scollon et al. 2003]. Irrespective of utilizing the snippetbased approach combined with contextual ESM, ultimately it was the participants who decided whether to respond to our probes or not. There may be cases where a participant is less likely to respond to a probe, or where it is impossible to respond to a probe. This means that that there will always be some situations that are less likely to get sampled (e.g., driving, swimming), and thus certain situations may be underrepresented in the resulting data.

Third, probing participants multiple times per day may also lead to a reactive effect [Scollon et al. 2003] — that is, the act of asking participants to tell us about their information needs too frequently could potentially interfere with their daily needs, experiences, and behaviors. Thus, probing our participants over a 3-month period about their information needs may have made our participants more aware of their information needs and thus caused some changes in their behaviors.

Finally, we used our participants' daily routines to inform our experience sampling algorithm and also allowed our participants to specify times of the day where they did not want to be probed. Our aim was to ensure that we probed our participants at the most appropriate, unobtrusive times and that response rates would not taper too much over the 3-month study duration. However, utilizing these daily routines to decide when to probe participants and allowing participants to specify blackout periods might also introduce some bias. In Section 4, we included a detailed analysis of our contextual ESM by examining the timestamps of the probes, the locations of probes, and the overall response rates. We were able to show that our algorithm was at least able to successfully probe our participants in diverse situations and locations and at varying times each day. Even with the blackout periods, we found that across all 108 participants, we were allowed to probe them approximately 11 hours each day on average. We also show that greater than $50 \%$ of the SMS snippets captured during the 3-month study duration were received within 45 minutes of sending an SMS probe. However, despite this analysis, it must be noted that there may be some activities, situations, times of day (e.g., nighttime), or days of the week (weekends) that are over- or undersampled.

Setting the right experimental design has a profound impact on the results obtained in all research studies [Myers 1997]. And mobility poses a completely new set of challenges to researchers, which means that methodologies developed in the past and for different domains need to be carefully adapted to the field of MobileHCI [Kjeldskov and Graham 2003]. We took great care to ensure that we deployed a carefully designed study that used a diverse and representative sample of participants, preserved ecological validity, and introduced as little sample bias as possible when probing participants. Thus, we are confident that the dataset described in this article is varied and rich, but we encourage future research in this space, particularly in utilizing difference methods and across different cultures and demographics to determine if our key findings still hold.

\section{CONCLUSIONS}

We have presented the results of one of the most comprehensive studies of daily information needs to date, spanning a 3-month period in Spain and capturing information 
needs in both mobile and nonmobile settings. By employing SMS, a contextual experience sampling algorithm, and an online Web diary, we gathered almost 12,000 SMS messages and more than 9,000 associated diary entries generated by more than 100 users. Through our large-scale, quantitative analysis, we have provided a number of key insights into the types of daily information needs that exist, how those information needs are addressed, and the impact of contextual and demographic factors on those needs.

Through our comparison to the Dearman et al. [2008] study, we have shown that there are recurring daily information needs, with needs related to finding, availability, and persons being the most popular in our study. We have shown that although people employ two main modalities for satisfying daily information needs (i.e., Internet access and asking for help), people generally employ a much wider range of modalities to satisfy their information needs. Furthermore, we discussed how the modality chosen to satisfy information needs is related to the type of information need in question. Our analysis of contextual, technological, and demographic factors revealed that the information needs that arise and the means chosen to satisfy those needs differ significantly between (1) men and women, (2) smartphone and feature phone users, and (3) mobile and fixed locations (e.g., home, work). Informed by these results, we outline a number of open research questions and implications. Overall, this article adds to a growing body of related work on understanding people's information needs. We hope the valuable real-world insights provided can help guide future research in this space and inform the design of new technologies aimed at assisting users in addressing their day-to-day information needs.

\section{REFERENCES}

Alia Amin, Sian Townsend, Jacco Ossenbruggen, and Lynda Hardman. 2009. Fancy a drink in Canary Wharf? A user study on location-based mobile search. In Proceedings of INTERACT'09. Springer-Verlag, Uppsala, Sweden, 736-749. http://oai.cwi.nl/oai/asset/14046/14046A.pdf.

Lisa F. Barrett and Daniel J. Barrett. 2001. An introduction to computerized experience sampling in psychology. Social Science Computer Review 19, 2 (Summer 2001), 175-185. http://www.affectivescience.org/pubs/2001/01CompExperSampling.pdf.

Frank R. Bentley and Crysta J. Metcalf. 2008. Location and activity sharing in everyday mobile communication. In Proceedings of Extended Abstracts on Human Factors in Computing Systems (CHI EA'08). ACM, New York, NY, 2453-2462. DOI : http://dx.doi.org/10.1145/1358628.1358702

Joel Brandt, Noah Weiss, and Scott R. Klemmer. 2007. txt 4 18r: Lowering the burden for diary studies under mobile conditions. In Proceedings of Extended Abstracts (CHI'07). ACM, New York, NY, 2303-2308. http://hci.stanford.edu/publications/2007/brandt_txt4l8r_chi2007_wip.pdf.

Iain Campbell. 2000. The Ostensive Model of Developing Information Needs. Ph.D. Dissertation. University of Glasgow, Glasgow, UK.

Li Chen and Luole Qi. 2010. A diary study of understanding contextual information needs during leisure traveling. In Proceedings of the Third Symposium on Information Interaction in Context (IIiX'10). ACM, New York, NY, 265-270. DOI : http://dx.doi.org/10.1145/1840784.1840823

Mauro Cherubini, Rodrigo de Oliveira, Anna Hiltunen, and Nuria Oliver. 2011. Barriers and bridges in the adoption of today's mobile phone contextual services. In Proceedings of Mobile Human-Computer Interaction Conference (MobileHCI'11). ACM Press, New York, NY.

Mauro Cherubini and Nuria Oliver. 2009. A refined experience sampling method to capture mobile user experience. In Proceedings of the International Workshop of Mobile User Experience Research (CHI'09), Yelena Nakhimovsky, Dean Eckles, and Jens Riegelsberger (Eds.). Boston, MA. https://sites.google.com/site/ chi09mobileworkshop/papers-upload/06_ExperienceSampling.pdf?attredirects=0

Alton Y. K. Chua, Radhika Shenoy Balkunje, and Dion Hoe-Lian Goh. 2011. Fulfilling mobile information needs: A study on the use of mobile phones. In Proceedings of the 5th International Conference on Ubiquitous Information Management and Communication (ICUIMC'11). ACM, New York, NY, Article 92, 7 pages. DOI : http://dx.doi.org/10.1145/1968613.1968721

Karen Church and Barry Smyth. 2009. Understanding the intent behind mobile information needs. In Proceedings of IUI'09. ACM, 247-256. 
Martin Colbert. 2007. Problems rendezvousing: A diary study. In Handbook of Mobile Human-Computer Interaction. Idea Group Publishing, London, UK, 1-23.

Sunny Consolvo and Miriam Walker. 2003. Using the experience sampling method to evaluate ubicomp applications. IEEE Pervasive Computing 2, 2 (April 2003), 24-31. DOI : http://dx.doi.org/10.1109/ MPRV.2003.1203750

David Dearman, Melanie Kellar, and Khai N. Truong. 2008. An examination of daily information needs and sharing opportunities. In Proceedings of the 2008 ACM Conference on Computer Supported Cooperative Work (CSCW'08). ACM, New York, NY, 679-688. DOI :http://dx.doi.org/10.1145/1460563.1460668

Nathan Eagle and Alex S. Pentland. 2006. Reality mining: Sensing complex social systems. Personal Ubiquitous Computing 10, 4 (March 2006), 255-268.

Joel E. Fischer. 2009. Experience-sampling tools: A critical review. In Proceedings of Mobile Living Labs 09: Methods and Tools for Evaluation in the Wild (MobileHCI'09). ACM.

Jon Froehlich, Mike Y. Chen, Sunny Consolvo, Beverly Harrison, and James A. Landay. 2007. MyExperience: A system for in situ tracing and capturing of user feedback on mobile phones. In Proceedings of the 5th International Conference on Mobile Systems, Applications and Services (MobiSys'07). ACM, New York, NY, 57-70. DOI : http://dx.doi.org/10.1145/1247660.1247670

Rebecca E. Grinter and Margery A. Eldridge. 2003. Wan2tlk?: Everyday text messaging. In Proceedings of ACM Conference on Human Factors in Computing Systems (CHI'03). Fort Lauderdale, FL, 441-448. http://www.cc.gatech.edu/ beki/c24.pdf

Tomi Heimonen. 2009. Information needs and practices of active mobile Internet users. In Proceedings of the 6th International Conference on Mobile Technology, Application and Systems (Mobility'09). ACM, New York, NY, Article 50, 8 pages. DOI :http://dx.doi.org/10.1145/1710035.1710085

Annika M. Hinze, Carole Chang, and David M. Nichols. 2010. Contextual queries express mobile information needs. In Proceedings of the 12th International Conference on Human Computer Interaction with Mobile Devices and Services (MobileHCI'10). ACM, New York, NY, 327-336. DOI :http://dx.doi.org/ $10.1145 / 1851600.1851658$

Stefan E. Hormuth. 1986. The sampling of experiences in situ. Journal of Personality 54, 1, 262-293. DOI : http://dx.doi.org/10.1111/j.1467-6494.1986.tb00395.x

Giovanni Iachello, Khai N. Truong, Gregory D. Abowd, Gillian R. Hayes, and Molly Stevens. 2006. Prototyping and sampling experience to evaluate ubiquitous computing privacy in the real world. In Proceedings of the SIGCHI Conference on Human Factors in Computing Systems (CHI'06). 1009. DOI : http://dx.doi.org/10.1145/1124772.1124923

Stephen S. Intille, John Rondoni, Charles Kukla, Isabel Ancona, and Ling Bao. 2003. A context-aware experience sampling tool. In Proceedings of Extended Abstracts on Human Factors in Computing Systems (CHI EA'03). ACM, New York, NY, 972-973. DOI : http://dx.doi.org/10.1145/765891.766101

Jesper Kjeldskov and Connor Graham. 2003. A review of mobile HCI research methods. In Human-Computer Interaction with Mobile Devices and Services. Springer, 317-335.

Daijiro Komaki, Takahiro Hara, and Shojiro Nishio. 2012. How does mobile context affect people's Web search behavior?: A diary study of mobile information needs and search behaviors. In Proceedings of the IEEE 26th International Conference on Advanced Information Networking and Applications (AINA). IEEE, 245-252.

Meredith Ringel Morris, Jaime Teevan, and Katrina Panovich. 2010. What do people ask their social networks, and why?: A survey study of status message q\&a behavior. In Proceedings of the SIGCHI Conference on Human Factors in Computing Systems (CHI'10). ACM, 1739-1748. DOI:http://dx.doi.org/ $10.1145 / 1753326.1753587$

Michael D. Myers. 1997. Qualitative research in information systems. Management Information Systems Quarterly 21, 241-242.

Leysia Palen and Marilyn Salzman. 2002. Voice-mail diary studies for naturalistic data capture under mobile conditions. In Proceedings of the 2002 ACM Conference on Computer Supported Cooperative Work (CSCW'02). ACM, New York, NY, 87-95. DOI : http://dx.doi.org/10.1145/587078.587092

Christie N. Scollon, Chu Kim-Prieto, and Ed Diener. 2003. Experience sampling: Promises and pitfalls, strengths and weaknesses. Journal of Happiness Studies 4, 1, 5-34.

Timothy Sohn, Kevin A. Li, William G. Griswold, and James D. Hollan. 2008. A diary study of mobile information needs. In Proceedings of the 26th Annual SIGCHI Conference on Human Factors in Computing Systems (CHI'08). ACM, New York, NY, 433-442. DOI : http://dx.doi.org/10.1145/1357054.1357125

Sakari Tamminen, Antti Oulasvirta, Kalle Toiskallio, and Anu Kankainen. 2004. Understanding mobile contexts. Personal Ubiquitous Computing 8, 135-143. https://www.hiit.fi/files/admin/sab/SAB04/material/ UERG/22_UMC_Puc2004_Oulasvirta.pdf. 
Robert S. Taylor. 1968. Question-negotiation and information seeking in libraries. College and Research Libraries 29, 178-194.

Jaime Teevan, Amy Karlson, Shahriyar, A. J. Bernheim Brush, and John Krumm. 2011. Understanding the importance of location, time, and people in mobile local search behavior. In Proceedings of the 13th International Conference on Human Computer Interaction with Mobile Devices and Services (MobileHCI'11). ACM, New York, NY, 77-80.

Martijn Vastenburg, Natalia Herrera, Juan Augusto, Juan Corchado, Paulo Novais, and Cesar Analide. 2010. Adaptive Experience Sampling: Addressing the Dynamic Nature of In-Situ User Studies. Vol. 72. Springer, Berlin, 197-200. DOI: http://citeseerx.ist.psu.edu/viewdoc/download?rep=rep1\&type= pdf\&doi=10.1.1.208.9338

Received October 2012; revised October 2013; accepted November 2013 